\title{
Assessing evolutionary consequences of size-selective recreational fishing on multiple life-history traits, with an application to northern pike (Esox lucius)
}

Shuichi Matsumura (matsumur@gifu-u.ac.jp)

Robert Arlinghaus (arlinghaus@igb-berlin.de)

Ulf Dieckmann (dieckmann@iiasa.ac.at)

\section{Approved by}

Detlof Von Winterfeldt

Director

July 2011 

1 Title

2 Assessing evolutionary consequences of size-selective recreational fishing on multiple

3 life-history traits, with an application to northern pike (Esox lucius)

4 Corresponding Author

$5 \quad$ Shuichi Matsumura

6 Faculty of Applied Biological Sciences, Gifu University, Yanagido 1-1, 501-1193 Gifu, Japan

7 phone +81-58-293-2874, email matsumur@gifu-u.ac.jp

8 Authors' names and addresses

9 Shuichi Matsumura ${ }^{1,2,3}$, Robert Arlinghaus ${ }^{2,4}$, and Ulf Dieckmann ${ }^{1}$

$10{ }^{1}$ Evolution and Ecology Program, International Institute for Applied Systems Analysis,

11 Schlossplatz 1, A-2361 Laxenburg, Austria.

$12{ }^{2}$ Department of Biology and Ecology of Fishes, Leibniz-Institute of Freshwater Ecology and 13 Inland Fisheries, Müggelseedamm 310, 12587 Berlin, Germany

$14{ }^{3}$ Faculty of Applied Biological Sciences, Gifu University, Yanagido 1-1, 501-1193 Gifu, Ja15 pan

$16{ }^{4}$ Inland Fisheries Management Laboratory, Department for Crop and Animal Sciences, Fac-

17 ulty of Agriculture and Horticulture, Humboldt-University of Berlin, Philippstrasse 13, Haus

187,10115 Berlin, Germany

19 


\section{Running title}

2 Fishing-induced life-history evolution in pike

\section{$3 \quad$ Keywords}

4 angling, evolutionarily enlightened fisheries management, fisheries-induced evolution, growth

5 rate, reproductive investment, size at maturation

\section{Word count}

7 Total: 7361 (Abstract: 275, Introduction: 950, Materials and Methods: 1862, Results: 2048,

8 Discussion: 2103, Acknowledgement: 115)

9 Number of cited references

$10 \quad 68$

\section{Number of tables and figures}

123 tables and 8 figures

13 Online appendix

14 None 


\section{Abstract}

2 Despite mounting recognition of the importance of fishing-induced evolution, methods for

3 quantifying selection pressures on multiple adaptive traits affected by size-selective harvest-

4 ing are still scarce. We study selection differentials on three life-history traits - reproductive

5 investment, size at maturation, and growth capacity - under size-selective exploitation of

6 northern pike (Esox lucius L.) with recreational-fishing gear. An age-structured population

7 model is presented that accounts for the eco-evolutionary feedback arising from density-

8 dependent and frequency-dependent selection. By introducing minimum-length limits, maxi-

9 mum-length limits, and combinations of such limits (resulting in harvestable-slot length lim-

10 its) into the model, we examine the potential of simple management tools for mitigating selec-

11 tion pressures induced by recreational fishing. With regard to annual reproductive investment,

12 we find that size-selective fishing mortality exerts relatively small positive selection differen-

13 tials. By contrast, selection differentials on size at maturation are large and consistently nega-

14 tive. Selection differentials on growth capacity are often large and positive, but become nega-

15 tive when a certain range of minimum-length limits are applied. In general, the strength of se-

16 lection is reduced by implementing more stringent management policies, but each life-history

17 trait responds differently to the introduction of specific harvest regulations. Based on a simple

18 genetic inheritance model, we examine mid- and long-term evolutionary changes of the three

19 life-history traits and their impacts on the size spectrum and yield of pike. In general, fishing-

20 induced evolution reduces sizes and yields, but details depend on a variety of factors such as

21 the specific regulation in place. We find no regulation that is successful in reducing to zero all

22 selection pressures on life-history traits induced by recreational fishing. Accordingly, we must

23 expect that inducing some degree of evolution through recreational fishing is inevitable. 



\section{Introduction}

2 Recently, questions regarding fishing-induced evolution have been attracting substantial at-

3 tention in the literature (for reviews, see Dieckmann and Heino 2007; Hutchings and Fraser

4 2007; Jørgensen et al. 2007; Kuparinen and Merilä 2007; Heino and Dieckmann 2008; Ander-

$5 \quad$ sen and Brander 2009; Dunlop et al. 2009a). As fisheries may impose remarkably high, and

6 often size-selective, mortalities on fish populations, they have the potential to cause evolu-

7 tionary changes in the life history, morphology, physiology, and behaviour of fish (Uusi-

8 Heikkilä et al. 2008). Empirical evidence suggesting strong selection pressures and rapid evo-

9 lutionary changes in life-history traits due to fishing is accumulating (e.g., Jørgensen et al.

10 2007; Darimont et al. 2009; Dieckmann et al. 2009; Dunlop et al. 2009a; Sharpe and Hendry

11 2009). Key future research questions are to quantify the strength of selection caused by specific fisheries on specific traits, the speed of the corresponding evolutionary changes, and the repercussions of these changes for fish populations and the ecological services they provide to society (Jørgensen et al. 2007; Dunlop et al. 2009a).

If current fishing practices cause substantial selection pressures on fish stocks, fisheries managers may want to identify effective ways to mitigate the strength of these pressures (Arlinghaus et al. 2009; Okamoto et al. 2009). In theoretical studies, different management policies have been examined by varying fishing selectivity between mature and immature fish (e.g., Heino 1998; Ernande et al. 2004), age classes (e.g., Law and Grey 1989; Grey 1993), size classes (e.g., Dunlop et al. 2009b), or by assuming representative shapes of size-selective exploitation (e.g., Jørgensen et al. 2009), in addition to changing harvest rates (e.g., Thériault et al. 2008; Enberg et al. 2009) and introducing marine reserves (e.g., Baskett et al. 2005; Dunlop et al. 2009c). However, more systematic investigations are required on a set of other management policies that have traditionally been used in, or are easily applicable to, fisheries. 
1 For example, some authors have suggested that saving large fish by applying maximum-

2 length limits will mitigate fishing-induced evolution (Conover and Munch 2002; Law 2007),

3 but so far only a few studies (Baskett et al. 2005; William and Schertzer 2005) have explored

4 the benefits of applying maximum-length limits relative to other management tools.

Another important issue is to evaluate the influences of fishing-induced evolution of

6 life-history traits on fisheries metrics. For example, large changes in life-history traits could

7 cause small changes in yield, because of the confounding effects of density dependence, phenotypic plasticity, or other ecological processes. By contrast, even small life-history changes may have a critical impacts (Kinnison et al. 2009), for example, on stock recovery or stock stability (Enberg et al. 2009). Because of these uncertainties, the importance of fishinginduced evolution for long-term population dynamics and fisheries yields remains controversial (Andersen and Brander 2009; Kinnison et al. 2009). Models are expected to play an important role in tackling the aforementioned issues, because systematic manipulation of management policies and evaluation of the resultant outcomes is usually not feasible in wild fish stocks. Crucial demographic effects on individual life histories, such as density-dependent growth (Lorenzen and Enberg 2002) and fecundity (Craig and Kipling 1983), need to be incorporated into demographic models. Model-based studies should also consider sufficiently encompassing sets of life-history traits, at least including traits describing evolutionary changes in growth, maturation, and reproduction. To date, only few studies have tackled this challenge using so-called eco-genetic models (Thériault et al. 2008; Dunlop et al. 2009b, c; Enberg et al. 2009; Okamoto et al. 2009). However, because these models are individual-based, their numerical implementation is computationally 23 more costly than that of age-structured population models, which makes their utilization by 24 fisheries managers more demanding (Arlinghaus et al. 2009). 
Fishing-induced evolution caused by recreational fisheries has not yet attracted much

2 attention in the literature. However, exploitation rates of fish stocks by recreational fisheries can be substantial, and most recreational fisheries are also selective for morphological and in addition to ecological changes, rapid evolutionary changes are expected to occur in response to the recreational exploitation of fish stocks (Arlinghaus et al. 2009; Philipp et al. 2009; Redpath et al. 2009), inter alia because stocks exploited by anglers often comprise small, isolated freshwater fish populations (Heino and Godø 2002; Lewin et al. 2006). Our previous study using an age-structured fish population model with angler exploitation and multi-dimensional density dependence (Arlinghaus et al. 2009) is among the few (see also Theriault et al. 2008; Saura et al. 2010) that explicitly dealt with recreational fisheries in the context of fishing-induced evolution. The objectives of the present study were (1) to quantify the selection strengths caused by recreational fishing on three different life-history traits, (2) to evaluate the effectiveness of different management policies to mitigate such selection, and (3) to examine possible evolutionary consequences of evolution induced by recreational fishing in terms of important stock variables such as average size at age and yield. Our model is based on northern pike, Esox lucius L., which is a common target of recreational fisheries (Paukert et al. 2001; Arlinghaus et al. 2008). To address our objectives, we extended our previous model, which considered only a single life-history trait (reproductive investment; Arlinghaus et al. 2009), to incorporate three life-history traits: growth capacity, size at maturation, and reproductive investment. In addition to minimum-length limits, which are the most commonly used harvest regulations in 23 pike (Paukert et al. 2001), we considered maximum-length limits and harvestable-slot length 24 limits, with the latter being designed to protect immature and large fish simultaneously (Arlinghaus et al. 2010). We deliberately constrained our study to such relatively simple harvest 
1 regulations, as these offer the greatest potential to be easily applied in the practices of recrea-

2 tional-fisheries management.

\section{Materials and Methods}

4 We use an age-structured population model parameterized for northern pike (hereafter simply

5 called pike) by integrating information available from various literature sources (Table 1). We

6 extend the model by Arlinghaus et al. (2009) to the simultaneous consideration of three im-

7 portant aspects of life history, i.e., reproduction, growth, and maturation. To promote general-

8 ity and reduce the number of parameters, we remove some of the density-dependent processes

9 considered by Arlinghaus et al. (2009) that were found to exert only small effects on estimates

10 of the selection strength on reproductive investment caused by recreational fishing. For a spe-

11 cific level of fishing mortality, we calculate selection differentials on all three life-history

12 traits, assuming that the population is at demographic equilibrium. Furthermore, we go be-

13 yond the original type of analysis conducted by Arlinghaus et al. (2009) by using our esti-

14 mates of the strength of selection to model the resultant evolutionary dynamics (Hilborn and

15 Minte-Vera 2008). Assuming a fixed heritability $\left(h^{2}=0.2\right)$, we thus predict evolutionary

16 changes in the three life-history traits caused by 100 years of fishing. In addition, we identify

17 the evolutionary endpoints at which selection pressures on all three traits vanish.

18 Below, we explain the key ingredients of our model. For more details, please see Ar-

19 linghaus et al. (2009).

20 Population dynamics

21 Using a Leslie population-projection matrix $\mathbf{K}(\mathbf{X}, \mathbf{E})$ that depends on life-history trait values

$22 \mathbf{X}$ and environmental variables $\mathbf{E}$, together with vectors $\mathbf{N}=\left(N_{1}, N_{2}, \ldots, N_{a_{\max }}\right)^{\mathrm{T}}$ that describe 
1 age-specific population densities (Caswell 2001), the population dynamics of a monomorphic

2 fish population are given by

$3 \quad$ (1a) $\mathbf{N}(t+1)=\mathbf{K N}(t)$,

4 with

5

$6 \quad \mathbf{K}(\mathbf{X}, \mathbf{E})=\left(\begin{array}{ccccc}f_{1}(\mathbf{X}, \mathbf{E}) y(\mathbf{X}, \mathbf{E}) & f_{2}(\mathbf{X}, \mathbf{E}) y(\mathbf{X}, \mathbf{E}) & \cdots & f_{a_{\max }-1}(\mathbf{X}, \mathbf{E}) y(\mathbf{X}, \mathbf{E}) & f_{a_{\max }}(\mathbf{X}, \mathbf{E}) y(\mathbf{X}, \mathbf{E}) \\ s_{1}(\mathbf{X}, \mathbf{E}) & 0 & \cdots & 0 & 0 \\ 0 & s_{2}(\mathbf{X}, \mathbf{E}) & \cdots & 0 & 0 \\ \vdots & \vdots & \ddots & \vdots & \vdots \\ 0 & 0 & \cdots & s_{a_{\max }-1}(\mathbf{X}, \mathbf{E}) & 0\end{array}\right)$

7

8 Here, $N_{a}(t)$ and $N_{a}(t+1)$ represent the density of fish at age $a$ years in years $t$ and $t+1$, re-

9 spectively. The survival probability of individuals from age $a$ to age $a+1$ is denoted by $s_{a}$,

$10 f_{a}$ is the fecundity (measured by the number of hatched eggs) at age $a$, and $y$ is the first-

11 year survival from hatched eggs to the age of 1 year. We consider a maximum age of

$12 a_{\max }=12$ years and assume that individuals at $a=a_{\max }$ die immediately after spawning

$13 \quad\left(s_{a_{\max }}=0\right)$. In the present study, $a$ thus varies between 1 and $a_{\max }$. The annual survival prob-

14 ability $s_{a}$ is given by

15

(2) $s_{a}=\left(1-m_{a}\right)\left(1-k_{a}\right)$,

16 where $0<m_{a}<1$ and $k_{a}$ are annual probabilities of natural mortality and angling mortality,

17 respectively. Age-specific fecundities $f_{a}$ and survival probabilities $s_{a}$, as well as the first-

18 year survival probabilities $y$, are functions of the life-history trait values $\mathbf{X}$ and the envi-

19 ronmental variables $\mathbf{E}$. The latter dependence represents density-dependent environmental

20 feedback. 
2 There are a multitude of models for describing the growth and maturation of fish. For our

3 evolutionary considerations, it is important to choose models that account for the trade-off be-

4 tween energy allocation to somatic growth and energy investment in reproduction (Dunlop et

5 al. 2009a). Also, to ensure wide applicability of the methods used for the present study, mod-

6 els with as few parameters as possible are preferred. Accordingly, we describe the growth tra-

7 jectory of fish based on the biphasic somatic growth model by Lester et al. (2004), which is a

8 special case of the model by Quince et al. (2008),

9

(3a) $\quad L_{a+1}=\frac{3}{3+g_{a}}\left(L_{a}+h\right)$,

(3b) $L_{1}=h\left(1-t_{1}\right)$,

11 where $g_{a}$ is the annual reproductive investment and $t_{1}<1$ is the age intercept of the pre-

12 maturation growth curve. The annual reproductive investment $g_{a}$ is represented as

$13 g_{a}=\omega G S I$, with the gonado-somatic index GSI (the ratio of gonad weight to somatic

14 weight) being weighted by a factor $\omega>1$ that captures the higher caloric density of gonad tis-

15 sue relative to somatic tissue. We define maturation as the start of energy allocation to reproduction, with first spawning occurring in the following year. In accordance with the original formulation by Lester et al. (2004), we assume a constant investment $g_{a}=g$ for all mature individuals, as opposed to $g_{a}=0$ for all immature individuals. Consequently, the annual length increment equals $h$ for juveniles $\left(g_{a}=0\right)$ and becomes smaller than $h$ after matura20 tion.

Following Dunlop et al. (2009a), the probability of becoming mature at age $a$ is de-

22 scribed as a function of the length $L_{a}$ at age $a$, 
$1 \quad(4 \mathrm{a}) \quad P_{\mathrm{m}, a}=\frac{1}{1+\exp \left(-\left(L_{a}-L_{\mathrm{p} 50}\right) / d\right)}$

2

(4b) $\quad d=\frac{v L_{\mathrm{p} 50}}{\operatorname{logit}\left(p_{\mathrm{u}}\right)-\operatorname{logit}\left(p_{1}\right)}$,

3 where $L_{\mathrm{p} 50}$ is the length at $50 \%$ maturation probability at age $a$ and $d$ determines the steep-

4 ness of the change in maturation probability around $L_{\mathrm{p} 50}$. The probabilities $p_{\mathrm{u}}$ and $p_{1}$ define

5 the upper and lower bounds of the probabilistic maturation envelope around $L_{\mathrm{p} 50}$ (for example,

$675 \%$ and $25 \%$, respectively), and $v$ determines the width of this envelope in units of $L_{\mathrm{p} 50}$

7 (Fig. 1a).

8 Density dependence

9 To obtain more realistic predictions, three mechanisms of density-dependent feedbacks on fit-

10 ness are incorporated in the model (Arlinghaus et al. 2009). First, somatic growth rates are as-

11 sumed to decrease as biomass density $D$ increases. Specifically, the annual juvenile growth

12 increment is defined as

13

(5) $\quad h=\frac{h_{\max }}{1+\gamma\left(D / D_{\mathrm{u}}\right)^{\delta}}$

14 where $h_{\max }$, called growth capacity, is the maximum juvenile growth increment realized for $D=0$, and $D_{\mathrm{u}}$ is a unit-standardizing constant.

17 increases,

18

(6) $f_{a}=\psi \frac{G_{a}}{2 W_{\mathrm{E}}} \exp (-\rho D)$

19 where $\psi$ is the hatching probability, $W_{\mathrm{E}}$ is the egg weight, and $G_{a}$ is the gonad weight of in-

20 dividuals at age $a\left(G S I=G_{a} / W_{a}\right)$. Parameters determining density-dependent relationships 
1 above are determined based on studies on pike in Lake Windermere, UK (Craig and Kipling

2 1983; Kipling 1983a, 1983b; see Table 1 and Arlinghaus et al. 2009 for details).

4 probability $y$ of hatched eggs during the first year depends on the density of hatched eggs,

5 with overcompensation,

6

(7) $\quad \log _{e} y=\lambda+\frac{\kappa B^{\mu}}{B^{\mu}+B_{1 / 2}^{\mu}}$,

7 where $\lambda$ is the logarithmic maximum survival probability, $\lambda+\kappa$ is the logarithmic minimum

8 survival probability, and $B_{1 / 2}$ and $\mu$ are parameters determining the shape of this overcom-

9 pensating density-regulation relationship. A Ricker stock-recruitment relationship seems to be

10 appropriate for cannibalistic pike (Edeline et al. 2008).

\section{Trade-offs and natural mortality}

12 The growth model by Lester et al. (2004) implies a trade-off between somatic growth and re13 productive investment (Fig. 1b). In addition, we assume a trade-off between somatic growth 14 and natural mortality. For individual fish, an increase in growth capacity typically necessitates

15 foraging in the face of predation risk and/or decreasing energy allocation to maintenance,

16 which are both likely to diminish survival (Stamps 2007). Incorporating such as trade-off is

17 crucial in models with evolving growth, because fish with infinitely fast growth could other-

18 wise evolve, which clearly is unrealistic. As the simplest representation (Dunlop et al. 2009a),

19 we assume that the annual survival probability declines linearly as growth capacity $h_{\max }$ in-

20 creases. The annual natural mortality probability $m_{a}$ is thus defined as

21

(8) $m_{a}=\left\{\begin{array}{cl}\tau h_{\max } & \text { if } h_{\max } \leq 1 / \tau \\ 1 & \text { if } h_{\max }>1 / \tau\end{array}\right.$, 
1 where $\tau$ determines the maximum growth capacity $1 / \tau$ beyond which survival is zero. The

2 value of $\tau$ is determined so that realised values of $h_{\max }$ in our hypothetical, non-exploited

3 population are within the range of values reported for pike populations in the field (Fig. 1c).

$4 \quad$ Fishing mortality

5 We consider three types of harvest regulations, which are widely used in recreational fisher-

6 ies: minimum-length limits (MinL-Ls), maximum-length limits (MaxL-Ls), and a combina-

7 tion of these (harvestable-slot length limits, HSL-Ls). The annual fishing mortality $k_{a}$ repre-

8 sents the proportion of fish removed from the population by recreational fishing, and is calcu-

9 lated as

10

(9) $\quad k_{a}=\left\{\begin{array}{cc}V_{a}[1-\exp (-F)] & \text { if } L_{\min } \leq L_{a} \leq L_{\max } \\ V_{a}[1-\exp (-\phi F)] & \text { otherwise }\end{array}\right.$,

11 where $F$ is the instantaneous fishing mortality, $\phi<1$ is the hooking mortality probability af-

12 ter catch-and-release, and $V_{a}$ (Fig. 1d) measures the portion of fish of age $a$ that is vulnerable

13 to angling (with other fish at age $a$ being invulnerable to angling, e.g., due to size-dependent

14 gape limitation to hooking or due to the choice of safe habitats; Post et al. 2003). Note that in

15 Arlinghaus et al. (2009) $F$ was represented as the product of a catchability coefficient and an

16 angling-effort density, but this representation was simplified in the present model. Note also

17 that we further simplified the model of Arlinghaus et al. (2009) by removing angling-effort

18 responses to changes in the density of vulnerable fish, as well as dynamically determined ille-

19 gal harvest, because these processes had little effect on estimates of the selection differentials

20 for reproductive investment (Arlinghaus et al. 2009). 
2 Selection differentials measure the change of a population's mean trait value before and after

3 selection (Falconer and Mackay 1996). Selection differentials for the three life-history traits

4 considered in this study are calculated after the population reaches demographic equilibrium.

5 We assume that the population's phenotypic variation is normally distributed around the

6 population mean, with a coefficient of variation given by $C V_{P}$. The selection differential $S$

7 on a trait $X$ is calculated as

8

(10) $S=\frac{\int X \lambda(X) p(X) d X}{\int \lambda(X) p(X) d X}-\frac{\int X p(X) d X}{\int p(X) d X}$,

9 where $p(X)$ and $\lambda(X)$ are the probability density and fitness of trait values $X$, respectively

10 (Arlinghaus et al. 2009). Thus, the second term represents the mean trait value before selec-

11 tion, and the first term represents the mean trait value after selection. The fitness of a rare

12 variant phenotype with a set of values $\mathbf{X}$ for the three life-history traits, in the resident popu-

13 lation of individuals whose trait values are identical to the population means, is calculated as

14 the dominant eigenvalue of the corresponding Leslie matrix $\mathbf{K}(\mathbf{X}, \mathbf{E})$ (Arlinghaus et al. 2009).

15 Selection differentials per generation are calculated using the dominant eigenvalue of the ma-

16 trix $\mathbf{K}^{T(\mathbf{X}, \mathbf{E})}(\mathbf{X}, \mathbf{E})$, where $T(\mathbf{X}, \mathbf{E})$ is the population's average generation time (Arlinghaus et 17 al. 2009).

Since the selection differential is not dimensionless, it must be standardized for comparing the selection strengths among traits or populations. In the present study, the mean-and-

20 variance-standardized selection differential (Arlinghaus et al. 2009), which has been referred

21 to in the literature as the mean-standardized selection gradient (Hereford et al. 2004), is calcu-

22 lated as

(11) $S_{\mathrm{std}}=\bar{X} \frac{S}{\sigma_{X}^{2}}$, 
1 where $\bar{X}$ is the population mean and $\sigma_{X}^{2}$ the population variance of the considered trait. The

2 mean-and-variance-standardized selection differential $S_{\text {std }}$ represents the increase in relative

3 fitness for a proportional change in the considered trait (Hereford et al. 2004). It is viewed as

4 a suitable dimensionless measure of selection strength, because it approximates the mean-

5 standardized slope of the trait's fitness landscape at the population mean $\bar{X}$ (Phillips and Ar-

6 nold 1989) and is largely independent of the population variance $\sigma_{X}^{2}$.

7 Outline of analysis

8 Our numerical investigations were based on parameter values representative for pike (Table

9 1). The initial population densities for the considered age classes were taken from long-term

10 data of the Windermere pike population (Kipling and Frost 1970). Angling intensity was var-

11 ied by modifying the instantaneous fishing mortality $F$. For a range of combinations of an-

12 gling intensity and harvest regulation, the analysis proceeded in two steps:

13 1. Estimation of selection differentials for the three life-history traits:

- We focused on the type and strength of selection that a pristine pike population experiences at the commencement of harvesting. The default set of population means of the three life-history traits was determined assuming that the present population is at evolutionary equilibrium in the absence of harvesting. Annual selection differentials $S$ for the three traits were then calculated for the default resident population.

2. Estimation of evolutionary changes in the three life-history traits:

- Using the annual selection differential $S$ and heritability $h^{2}$ for each trait, its selection response was obtained as $R=h^{2} S$ (Falconer and Mackay 1996). The trait's population mean for the next year was then obtained by adding the selection response to the current population mean. 
- This procedure was repeated for 100 years. The rate of evolution, in the unit Darwin, was calculated as $r=\left|\ln z_{2}-\ln z_{1}\right| /\left(t_{2}-t_{1}\right)$, where $z_{1}$ and $z_{2}$ are the trait's population means at the beginning $\left(t_{1}\right)$ and end $\left(t_{2}\right)$ of the considered period and the duration $t_{2}-t_{1}$ was measured in millions of years.

- Possible evolutionary endpoints, where the selection differentials $S$ vanish for all three traits, were identified by changing values of the three traits systematically. In general, the procedure above was extended until the population reaches equilibrium. Even when an evolutionary endpoint was identified, the procedure was repeated for several different starting values because there may exist alternative equilibrium states.

\section{Results}

\section{Evolutionary equilibria in the absence of fishing}

To determine the initial conditions for studying fishing-induced evolution, we consider a fish population that is not yet exposed to fishing pressures. Specifically, we assume that this population has evolved to an evolutionary equilibrium, which implies that the selection pressures on all three life-history traits vanish. We found two combinations of population means for the three life-history traits that yield zero selection differentials (Table 2), representing alternative possible evolutionary endpoints (EP). The first trait combination (EP-1) is characterised by early maturation (at the age of 1 year), while the second trait combination (EP-2) is characterised by later maturation (at the age of 2 or 3 years). Accordingly, spawning occurs at the age of 2 years in the EP-1 population and at the ages of 3 and 4 years in the EP-2 population. Although selection differentials are zero in the EP-1 population with the default degree of phenotypic variation, individuals with the EP-2 population means can invade into the EP-1 population, because their fitness is higher than that of the residents. By contrast, individuals with 
1 the EP-1 population means cannot invade into the EP-2 population, because their fitness is

2 lower than that of the residents. In other words, only the EP-2 population is evolutionarily

3 stable. Therefore, we focus on EP-2 as a baseline condition for investigating the consequences

4 of fishing. The age and size at maturation in the EP-2 population agree well with empirical

5 values reported for pike populations (Raat 1988).

6 Fishing-induced evolution in the absence of harvest regulations

7 We started our investigation by examining the situation without harvest regulation. As ex-

8 pected, the magnitude of selection differentials for the three traits increases with increasing

9 recreational-fishing mortality (Fig. 2a). Selection differentials for reproductive investment $g$

10 and growth capacity $h_{\max }$ are both positive, so that the traits experience selection pressures

11 towards increasing reproductive investment and growth capacity. The standardized strength of

12 selection on growth is larger than that on reproductive investment, especially when the an-

13 gling intensity is high. The standardized selection differential on the size at maturation $L_{\mathrm{p} 50}$ is

14 as large as that on $h_{\max }$, but the direction is opposite, so that this trait experiences selection

15 pressures towards decreasing size at maturation. The fishing yield (harvested biomass) from

16 the population is maximized at an instantaneous fishing mortality of $F \approx 0.4$ (Fig. 2b), and

17 selection differentials are relatively small when the population is not overexploited (Fig. 2a),

18 i.e., when fishing mortality remains below the fishing mortality at maximum sustainable yield.

19 Effects of harvest regulations on selection strengths

20 Next, we systematically investigated the effects of harvest regulations on selection differen-

21 tials. In general, increasing minimum-length limits (MinL-Ls) mitigate the magnitude of se-

22 lection differentials, but this effect differs greatly between the three evolving traits (Fig. 3a-c).

23 The magnitudes of selection differentials on reproductive investment $g$ exhibit a peak at in- 
1 termediate MinL-Ls (Fig. 3a). MinL-Ls have a strong impact on selection differentials on

2 growth capacity $h_{\max }$ (Fig. 3b): introduction of a MinL-L of $45 \mathrm{~cm}$ causes positive selection

3 differentials for this trait, but these change to negative at a MinL-L of about $50 \mathrm{~cm}$, and val-

4 ues approach zero as the MinL-L is increased further. The magnitude of selection differentials on the size $L_{\mathrm{p} 50}$ at maturation first slightly increases as the MinL-L increases up to $60 \mathrm{~cm}$, and then decreases as the MinL-L is increased further (Fig. 3c).

We also investigated the effects of other types of harvest regulations, i.e., harvestableslot length limits (HSL-L; Fig. 3d-f) and maximum-length limits (MaxL-L; Fig. 3g-i). The magnitude of selection differentials for $g$ is generally smaller than in the absence of harvest regulations. The curvatures of the relationships between selection differentials for $g$ and the tightness of harvest regulations are almost opposite to the MinL-L case, with the lowest selection differentials resulting for intermediate harvest regulations. The selection differentials for $h_{\max }$ are large and positive, and decline relatively suddenly for tight HSL-L harvest regulations. Selection differentials for $L_{\mathrm{p} 50}$ are usually negative, and their magnitude decreases as regulations become stricter. They become even positive under the strictest HSL-L and MaxLL harvest regulations.

To understand regulation-specific differences in the mitigation of selection pressures in more detail, we examined selection differentials for exploitation levels that result in identical reductions of spawner biomasses, as quantified by the spawning-potential ratio (Fig. 4). For MinL-L regulations, selection pressures on $g$ are larger, those on $h_{\max }$ are generally

21 smaller, and those on $L_{\mathrm{p} 50}$ are also smaller than without harvest regulations, because smaller sizes have a selective advantage under MinL-L regulations. Opposite trends are found in the selection pressures under HSL-L and MaxL-L regulations, because larger sizes have a selective advantage in these cases. It turned out that the selection strengths under harvest regula- 
1 tions are often larger than those without harvest regulations for the same level of exploitation.

2 This means that the effects of harvest regulations on mitigating selection pressures, as seen in

3 Fig. 3, actually result from the reduction of exploitation levels rather than from altered selec-

4 tivity patterns in terms of vulnerable fish sizes. In fact, for the same exploitation levels, the

5 more pronounced selectivity patterns associated with harvest regulations result in stronger se-

6 lection pressures than the less selective exploitation patterns that apply in the absence of har-

7 vest regulations.

8 Evolutionary changes of traits and their consequences

9 We investigated evolutionary changes in the three life-history traits, and resultant changes in population characteristics, when a fixed angling pressure was continuously applied for a

11 longer period (Fig. 5-7). Specifically, we followed changes in trait values, fish length at the age of 4 years, and yield (harvested biomass) during 100 years of fishing (Fig. 5a). Essentially linear changes in the values of the three life-history traits for 100 years imply that selection pressures remain virtually constant during this period. Accordingly, the selection strengths at the beginning of this period, represented by standardized selection differentials $S_{\text {std }}$ and estimated as described in the preceding section, are good predictors of the evolutionary outcomes 17 after 100 years. During this period, reproductive investment $g$ and growth capacity $h_{\max }$ increase by $5 \%$ and $10 \%$, respectively, while size $L_{\mathrm{p} 50}$ at maturation decreases by $8 \%$ when no harvest regulation is adopted. The evolutionary trait changes tend to increase $\left(h_{\max }\right)$ or decrease $\left(g\right.$ and $\left.L_{\mathrm{p} 50}\right)$ fish 21 length at age 4. As a result of these conflicting effects, adult fish length at the age of 4 years increases by $5 \%$ after 100 years of harvesting without regulation (from $76.7 \mathrm{~cm}$ to $81.2 \mathrm{~cm}$ ). By contrast, the yield shows little change. When harvest regulations are introduced, adult fish 24 length at the age of 4 years becomes either larger (with MaxL-Ls or HSL-Ls) or smaller (with 
1 MinL-Ls) than in the unexploited case. In some cases, yield drops by $10-20 \%$ as evolutionary

2 changes enable fish to escape the harvestable size ranges. Under HSL-Ls, increases in yield

3 result from increased fish length at the age of 4 years (from about $72 \mathrm{~cm}$ to about $78 \mathrm{~cm}$ ),

4 while the number of harvested individuals decreases by more than $10 \%$.

We also compared the values after 100 years with those at the possible evolutionary endpoints (Fig. 6). At the evolutionary endpoint, fish length at the age of 4 years is ca. $50 \%$ smaller when a MinL-L of $45 \mathrm{~cm}$ is applied than without fishing-induced evolution (Fig. 6a). Evolution towards small size becomes less pronounced as MinL-Ls is increased. Applying MaxL-Ls causes the opposite effect: in contrast to MinL-Ls, fish length at the evolutionary endpoint is larger than without fishing-induced evolution (Fig. 6i). The largest evolutionary change is observed for an intermediate MaxL-L of $75 \mathrm{~cm}$. When HSL-Ls are introduced by combining a MinL-L of $45 \mathrm{~cm}$ with various MaxL-Ls, two distinct outcomes occur depending on whether the MaxL-L is large $(\geq 80 \mathrm{~cm})$ or small $(\leq 75 \mathrm{~cm})$ (Fig. 6e). Fish become considerably smaller in the former case, whereas they become larger in the latter case. It appears contradictory that in some cases fish length after 100 years is larger than without fishing-induced evolution, even though fish length at the evolutionary endpoint is considerably smaller than without fishing-induced evolution: this occurs for HSL-Ls with a MinL-L of $45 \mathrm{~cm}$ and a large MaxL-L. The reason is that fish length increases for the first few hundred years due to the positive selection on growth capacity (Fig. 7). Once the positive selection on growth capacity stops, because its fitness advantage vanishes due to the trade-off between growth and survival, adult fish length decreases continuously, mainly due to positive selection on reproductive investment. In most cases, yield at the evolutionary endpoint is much smaller than prior to fishinginduced evolution (Fig. 6b, 6f, 6j). Exceptions appear for a MinL-L of $100 \mathrm{~cm}$ and for large MaxL-Ls ( $\geq 80 \mathrm{~cm})$, i.e., for cases in which the original yield is extremely small. In many 
1 cases, also population biomass at the evolutionary endpoint is smaller than prior to fishing-

2 induced evolution (Fig. 6c, 6g, 6k). By contrast, if a MinL-L of $45 \mathrm{~cm}$ or HSL-Ls are applied,

3 population biomass can be twice as large as prior to fishing-induced evolution. In these cases,

4 the population contains a large number of fish that are smaller than $45 \mathrm{~cm}$. At the evolution-

5 ary endpoint, the pristine population biomass, i.e., the equilibrium population biomass that is

6 attained when fishing is ceased, is considerably smaller (by up to 60\%) than prior to fishing-

7 induced evolution (Fig. 6d, 6h, 61).

\section{Robustness analyses}

9 The robustness of results of our model-based analysis was tested by altering the underlying assumptions or default parameter values. According to our original assumption, almost all fish

11 at ages 2 years or older are equally vulnerable to angling (Fig. 1d, continuous line). In other words, the difference in size selectivity on older fish is not very pronounced, in line with empirical data for recreational pike fisheries, where only the very small juvenile fish (with a total length of less than $20 \mathrm{~cm}$ ) are not vulnerable to angling, while fish over $40-50 \mathrm{~cm}$ are equally vulnerable (Pierce et al. 1995). We shifted the original vulnerability curve to the right, so that target fish are restricted to much larger sizes than in the default case (Fig. 1d, dashed line). Such a shift, to which we refer as trophy selectivity, may be expected, for example, when an18 glers start using large lures (Arlinghaus et al. 2008). Under such situations of more pronounced size selectivity, large positive selection on growth capacity $h_{\max }$, which often occurs for the original size selectivity, is not observed, even in the absence of harvest regulations (Fig. 5b). Accordingly, fish size and yield decline during 100 years in the absence of harvest regulation. Evolutionary changes become small for stringent harvest regulations (HSL-L of 45-60 cm or MaxL-L of $50 \mathrm{~cm}$ ). This is because almost no legal harvest is possible under the joint impact of these regulations and trophy selectivity. 
Next, the phenotypic variability and heritability of the evolving traits are modified to

2 test the impact of these variables on the magnitude of evolutionary change (Fig. 8). As ex-

3 pected, this magnitude increases almost linearly with heritability. By contrast, the influence of

4 phenotypic variability on evolutionary change is more significant and complicated. When the

5 phenotypic coefficient of variation is $5 \%$, evolutionary changes are almost negligible. When

6 the phenotypic coefficient of variation is $20 \%$, considerably larger evolutionary changes are

7 observed, in particular in growth capacity. This large impact is a result of the fact that the de-

8 gree of phenotypic variability crucially affects whether or not variant individuals with trait

9 values that strongly depart from the current population means exist in the population: since,

10 due to the nonlinearity of the fitness landscape, these individuals may possess extremely high

11 fitness, they have a large impact on the resultant magnitude of evolutionary changes.

Results of sensitivity analyses for other parameters are summarized in Table 3. In gen-

eral, predictions about reproductive investment are more robust to changes in parameter val-

ues than those about growth capacity or size at maturation. The latter two life-history traits are

sensitive to the trade-off between growth and survival (described by the parameter $\tau$ ). An in-

crease in $t_{1}$, the age intercept of the pre-maturation growth curve, greatly intensifies selection

on growth, via changes in the vulnerability to angling around the age at first spawning. Other parameters that relatively exert strong impacts on model predictions are the exponents in the

19 allometric length-weight regression $(\beta)$, in the stock-recruitment relationship determining

20 density-dependent larval survival ( $\lambda$ and $\mu$ ), and in the relationship between fish length and 21 vulnerability to fishing $(\eta)$.

\section{Discussion}

The present study has demonstrated how recreational fishing causes considerable selection pressures on multiple life-history traits under various types of fishing regimes. In the absence 
1 of harvest regulations, these selection pressures elevate energy allocations to reproduction,

2 maturation, and growth. Selection strengths on maturation size and growth capacity exceed

3 those on reproductive investment. The present study has also illustrated the complex nature of

4 fishing-induced life-history selection: for example, the direction and magnitude of selection

5 on growth capacity changes drastically when the size-selectivity of harvesting is strengthened

6 by large minimum-length limits (MinL-Ls) or trophy-size-oriented recreational harvesting.

A primary goal of our work here was to systematically investigate the effects of different types of harvest regulations on the strengths of fishing-induced selection on several lifehistory traits. In addition to MinL-Ls, we therefore considered maximum-length limits (MaxL-Ls) and harvestable-slot length limits (HSL-Ls), with the latter being designed to pro11 tect immature and large fish simultaneously (Arlinghaus et al. 2010). Applying different MinL-Ls is one of the most common harvest regulations in recreational fisheries (Paukert et al. 2001). We find that MinL-Ls generally work well in mitigating the strength of fishing-induced selection, in particular, on growth capacity and maturation size. Although MinL-Ls strengthen the size-selectivity of harvesting, larger MinL-Ls usually reduce selection strengths. The direction of selection on growth capacity is positive for the smallest considered MinL-L (45 cm), but becomes negative as MinL-Ls are raised. In interpreting these findings, it is crucial to remember that the mitigation of selection achieved by MinL-Ls in our model largely results from the implied reduction of exploitation rates. If, in contrast, fishing efforts are adjusted so as to keep yield (and income) constant, despite the altered harvest regulations, larger MinL-Ls could instead intensify selection.

Application of MaxL-Ls has been suggested as an alternative to MinL-Ls to reduce the strength of fishing-induced selection pressures (Conover and Munch 2002). It seems intuitively plausible to assume that MaxL-Ls might counteract the effects of positively sizeselective fishing. Corroborating this expectation, we find that selection strengths, in particular, 
on maturation size, can indeed be reduced through MaxL-Ls. At the same time, however,

2 MaxL-Ls greatly increase the magnitude of positive selection on growth capacity.

Also HSL-Ls have been suggested for mitigating fishing-induced evolution (Law

2007). The present study has shown that HSL-Ls change fishing-induced selection pressures

similar to MaxL-Ls. Selection on reproductive investment can be reduced effectively, while selection on growth capacity is considerably strengthened, and is usually positive just as for high MinL-Ls. Nevertheless, HSL-Ls have been shown to be effective in reducing selection on maturation size, both in our model and elsewhere (Baskett et al. 2005). Similarly, Jørgensen et al. (2009) have argued that bell-shaped size-selectivity, which obviously is akin to HSL-Ls, better mitigates fishing-induced evolution than sigmoid size-selectivity. Arlinghaus et al. (2010) reported additional advantages of HSL-Ls over MinL-Ls for managing pike, including increased harvest biomass, elevated abundance of trophy fish, and reduced truncation of the population's age structure. Based on these findings, further investigations of the potential of HSL-Ls as a tool of recreational-fisheries management are warranted. harvesting clearly underscore that one should not trust the often-reported intuition that fishing-induced evolution will necessarily reduce the growth rates of fish in response to positively size-selective fishing (sensu Walters and Martell 2004). Despite some empirical studies (e.g., Ricker 1981; Conover and Munch 2002; Swain et al. 2007; Nusslé et al. 2008), only few theoretical investigations have so far examined growth evolution caused by size-selective fishing (William and Schertzer 2005; Hilborn and Minte-Vera 2008). In agreement with our study, recent empirical investigations have reported less-than-straightforward patterns in fishinginduced selection on growth. In particular, using an individual-based eco-genetic model, Dunlop et al. (2009b) predicted positive evolutionary changes in genetic growth capacity for small MinL-Ls, although they found negative changes for other MinL-Ls. Also the present 
1 model predicts such changes in the direction of selection pressures on growth capacity: al-

2 though selection is positive and strong for small MinL-Ls $(45 \mathrm{~cm})$, it becomes negative and

3 weak for larger MinL-Ls. It seems clear that the direction of selection on growth capacity de-

4 pends not only on the size-selectivity of fishing, but also on the life history of the fished spe-

5 cies. If the species matures at small sizes, while fishing is limited to very large fish (as im-

6 plied by large MinL-Ls), the number of reproductive opportunities increases for fish staying

7 below MinL-L. Thus, slow growth will be favoured by evolution. This is not the case if fishing also targets small fish (as implied by small MinL-Ls or non-selective exploitation). Under such conditions, fast growth may be favoured by evolution, because growing as quickly as possible and having a single successful spawning event might then be advantageous. Given the life history of pike (early maturation at small size) and considering its typical exposure to steep size-selectivity curves (Pierce et al. 1995), positive selection on growth must be expected when pike is managed by small MinL-Ls of $45-50 \mathrm{~cm}$.

MaxL-Ls must also be expected to favour faster-growing fish, because these increase their chances of avoiding harvesting by growing into the protected size range. Therefore, if the baseline harvesting scheme in the absence of harvest regulations causes negative selection on growth, as in the case examined by William and Schertzer (2005), MaxL-Ls might counteract the baseline selection, and thus decrease the strength of selection on growth. However, if the baseline selection on growth is positive, as in the present study, MaxL-Ls further increase the strength of selection on growth.

Surely the argument above is sensitive to assumptions of size-dependent mortality and fecundity (Thygesen et al. 2005). Except for the first year of life, our model considered a constant, size-independent natural mortality, which was assumed to be a function of growth rate to represent the theoretically sound idea of a growth-survival trade-offs (Stamps 2007). However, positively size-dependent survival resulting from higher chances of escaping cannibal- 
1 ism as body size increases might also be found in adult pike (Haugen et al. 2007). Further-

2 more, our model assumed a constant gonado-somatic index after maturation, even though it is

3 known that it increases with the size of mature female pike (Edeline et al. 2007). Structural

4 changes to our model will therefore be needed to examine the implications of size dependence

5 in natural mortality and gonado-somatic index for estimates of fishing-induced evolution.

It is worth highlighting that, in terms of the practical consequences of fishing-induced evolution, positive selection on growth in the present study had a large effect on pike yield as measured by harvested biomass. To date, there have only been a few attempts to quantify yield changes resulting from fishing-induced evolution, and most of them predicted yield to decline (Law and Grey 1989; Heino 1998; Andersen and Brander 2009; Okamoto et al. 2009).

11 Also experiments have demonstrated declining yields in response to size-selective exploitation (Conover and Munch 2002). In the present study, however, fishing-induced life-history evolution increased yield for some harvest regulations such as HSL-Ls. The difference between previous results and our findings arises from evolutionary trends in fish size caused by fishing. In many previous models, only maturation age could evolve, with its decline in response to fishing resulting in smaller fish. In our study, adult fish size often increased as the effects of increased growth capacity outweighed those of smaller maturation size and elevated reproductive investment.

The three life-history traits examined here exhibited considerable evolutionary changes. For example, we found an increase in growth capacity of up to $13 \%$ within 100 years of fishing with an instantaneous mortality of 0.67 year $^{-1}$. During those 100 years, evolutionary changes were almost linear in time, which implies that the direction and strength of directional selection were almost constant. The initial selection strength represented by $S_{\text {std }}$ thus appears to be a good predictor of the amount of evolutionary changes accruing during 100 years. Based on the maximum value of $S_{\text {std }}$ on growth, which occurs for very high angling in- 
1 tensities, growth capacity may evolutionarily increase by up to $40 \%$ during 100 years of fish-

2 ing. A 13-40\% increase during 100 years corresponds to an evolutionary rate of $1.2-3.4 \times 10^{3}$

3 Darwin. This rate is modest compared to values reported for fishing-induced evolution in

4 commercial fisheries (Jørgensen et al. 2007; Sharpe and Hendry 2009). Andersen and Brander

5 (2009) concluded in a modelling study that the rate of fishing-induced evolution is slow, but

6 their estimates $(\approx 0.1-0.6 \%$ change in phenotypes per year, which is equivalent to 1.0 -

$76.0 \times 10^{3}$ Darwin) are well in line with our estimated evolutionary rates here. Therefore, dis-

8 cussions of whether fishing-induced evolution is "fast" or "slow" are not overly meaningful

9 without establishing a natural baseline against which to judge evolutionary rates. Moreover,

10 as our robustness analysis has shown, the rate of evolution is influenced by the degree of phe-

11 notypic variance and heritability. Unfortunately, good estimates of these parameters are ex-

12 ceedingly rare for wild fish stocks. Moreover, genetic and phenotypic variances, and hence

13 the corresponding heritabilities, might readily change during the course of evolution (Edeline

14 et al. 2009), with obvious consequences for the speed of fishing-induced evolution.

How do our estimated rates of life-history evolution in response to recreational fishing compare with field observations for pike? Qualitatively, our prediction that exploitation of

17 pike results in increased reproductive investment well agrees with field observations of pike

18 populations exposed to differential angling mortality (Diana 1983). Diana (1983) also observed pike populations to mature earlier when exposed to high adult mortality through angling, which again agrees with our findings, but the empirical study did not control for a potential compensatory response, which provides an alternative explanation of earlier maturation through relaxed competition for food.

The only empirical estimates of fishing-induced evolution in the growth rate of pike stems from long-term demographic analyses of the pike population in Lake Windermere 
1 experimental exploitation with gill nets, with a maximum annual exploitation fraction of $8 \%$

2 (Edeline et al. 2007). One must be careful, however, when trying to directly compare the em-

3 pirical findings from Windermere with our model predictions. This is for two reasons. First,

4 exploitation levels, types of fishing gears, and the implied size-selectivity in Windermere

5 strongly differed from the simpler assumptions made in our recreational-fisheries pike model.

6 Second, interpreting any observed phenotypic changes in adult growth rates (as provided by

7 the Windermere studies) is complicated by the potential joint evolution of growth capacity, maturation schedule, and reproductive investment. Yet, it is noteworthy that natural and fish-

9 ing-induced selection on body size in Windermere pike appeared to act in opposite directions: small adult pike are disfavoured by natural selection, but favoured by fishing-induced selection (Carlson et al. 2007; Edeline et al. 2009). Consequently, somatic growth of adult pike decreased when the experimental gill-net fishery was intensified, but increased after experimental fishing was relaxed (Edeline et al. 2007, 2009). The evolution of slower growth in Windermere pike agrees with our model predictions for a MinL-L of $60 \mathrm{~cm}$ (Windermere pike below $60 \mathrm{~cm}$ were not intensively exploited, so the experimental fishery may be viewed as effectively exploiting adult pike according to a MinL-L of $60 \mathrm{~cm}$ ). Another important insight from the Windermere studies is that the gill-net fishery resulted in disruptive selection favouring both small- and large-sized pike through a bell-shaped selectivity curve (Carlson et al. 2007; Edeline et al. 2009). This disruptive selectivity appears to have increased the genetic variability for somatic growth of adult pike, thus enabling the rapid evolutionary rebound observed in somatic growth after fishing intensity was relaxed (Edeline et al. 2009). Even though the HSL-Ls in the present study resemble the disruptive se23 lectivity caused by gill nets in Windermere, we cannot immediately use our model to investigate the rapid evolutionary rebound, because we only considered a constant genetic variance. 
1 Including the effects of fishing on genetic variability thus provides a natural and interesting

2 extension of our model.

The present study showcases the complexity exploited fish populations can exhibit in response to fishing activities and regulations. It underscores the need for the development and analyses of stock-specific models, to fully understand observed ecological and evolutionary responses to fishing. When applied to pike, future stock-specific models could include sizedependent mortality processes in general, and size-dependent cannibalism in particular. Despite these opportunities for extension, our study clearly demonstrates that no regulation can reduce to zero all selection pressures induced by size-selective recreational fishing. Thus, managers will likely have to cope with recreational fishing-induced evolution in all inten-

11 sively exploited pike populations. Independently of whether such evolution is beneficial (e.g., when it increases fish size) or detrimental (e.g., when it reduces yield), its existence should no longer be ignored in recreational-fisheries management.

\section{Acknowledgements}

This research was supported by the Leibniz-Community Pact for Innovation and Research by a grant to RA for the project Adaptfish (www.adaptfish.igb-berlin.de). Further funding was received by RA by the German Ministry for Education and Research (BMBF) through the Program for Social-Ecological Research (SOEF) within the project Besatzfisch (grant \# 01UU0907, www.besatz-fisch.de). UD gratefully acknowledges financial support by the European Commission, through the Marie Curie Research Training Network FishACE (contract MRTN-CT-2004-005578) and the Specific Targeted Research Project FinE (contract SSP-2006-044276), funded under the European Community's Sixth Framework Program. UD received additional support by the European Science Foundation, the Austrian Science Fund, the Austrian Ministry of Science and Research, and the Vienna Science and Technology Fund. 


\section{References}

2 Andersen KH, Brander K (2009) Expected rate of fisheries-induced evolution is slow. Proc Nat Acad Sci USA 106:11657-11660

4 5

6

7

Arlinghaus R, Klefoth T, Kobler A, Cooke SJ (2008) Size-selectivity, capture efficiency, injury, handling time and determinants of initial hooking mortality of angled northern pike (Esox lucius L.): the influence of bait type and size. N Am J Fish Manage 28:123134

Arlinghaus R, Mehner T, Cowx IG (2002) Reconciling traditional inland fisheries management and sustainability in industrialized countries, with emphasis on Europe. Fish Fish 3: $261-316$

Arlinghaus R, Matsumura S, Dieckmann U (2009) Quantifying selection differentials caused by recreational fishing: development of modeling framework and application to reproductive investment in pike (Esox lucius). Evol Appl 2:335-355

Arlinghaus R, Matsumura S, Dieckmann U (2010) The conservation and fishery benefits of protecting large fish from exploitation: the example of pike (Esox lucius L.) exploited by recreational fisheries. Biol Conserv 143:1444-1459

Baskett ML, Levin SA, Gaines SD, Dushoff J (2005) Marine reserve design and the evolution of size at maturation in harvested fish. Ecol Appl 15:882-901

Carlson SM, Edeline E, Vøllestad LA, Haugen TO, Winfield IJ, Fletcher JM, Ben James J, Stenseth NC (2007) Four decades of opposing natural and human-induced artificial selection acting on Windermere pike (Esox lucius). Ecol Lett 10:512-521

Caswell H (2001) Matrix population models. Sinauer Associates, Sunderland

Conover DO, Munch SB (2002) Sustaining fisheries yields over evolutionary time scales. Science 297:94-96 
1 Craig JF, Kipling C (1983) Reproduction effort versus the environment; case histories of Windermere perch, Perca fluviatilis L., and pike, Esox lucius L. J Fish Biol 22:713-727

Darimont CT, Carlsonc SM, Kinnisond MT, Paquete PC, Reimchena TE, Wilmersbet CC (2009) Human predators outpace other agents of trait change in the wild. Proc Nat Acad Sci USA 106:952-954

Diana JS (1983) Growth, maturation, and production of northern pike in three Michigan lakes. Trans Am Fish Soc 112:38-46

Dieckmann U, Heino M (2007) Probabilistic maturation reaction norms: their history, strengths, and limitations. Mar Ecol Prog Ser 335:253-269

Dieckmann U, Heino M, Rijnsdorp AD (2009). The dawn of Darwinian fishery management. ICES Insight 46:34-43

Dunlop ES, Enberg K, Jørgensen C, Heino M (2009a) Toward Darwinian fisheries management. Evol Appl 2:245-259

Dunlop ES, Heino M, Dieckmann U (2009b) Eco-genetic modeling of contemporary lifehistory evolution. Ecol Appl 19:1815-1834

Dunlop ES, Baskett ML, Heino M, Dieckmann U (2009c) Propensity of marine reserves to reduce the evolutionary effects of fishing in a migratory species. Evol Appl 2:371-393

Edeline E, Carlson SM, Stige LC, Winfield IJ, Fletcher JM, Ben James J, Haugen TO, Vøllestad LA, Stenseth NC (2007) Trait changes in a harvested population are driven by a dynamic tug-of-war between natural and harvest selection. Proc Nat Acad Sci USA 104:15799-15804

Edeline E, Carlson SM, Ben Ari T, Vøllestad LA, Winfield IJ, Fletcher JM, Ben James J, Stenseth NC (2008) Antagonistic selection from predators and pathogens alters foodweb structure. Proc Nat Acad Sci USA 105:19793-19796 
1 Edeline E, Le Rouzic A, Winfield IJ, Fletcher JM, Ben James J, Stenseth NC, Vollestad LA (2009) Harvest-induced disruptive selection increases variance in fitness-related traits. Proc R Soc B 276:4163-4171

Enberg K, Jørgensen C, Dunlop ES, Heino M, Dieckmann U (2009) Implications of fisheriesinduced evolution for stock rebuilding and recovery. Evol Appl 2:394-414

Ernande B, Dieckmann U, Heino M (2004) Adaptive changes in harvested populations: plasticity and evolution of age and size at maturation. Proc R Soc Lond B 271:415-423

Falconer DS, Mackay TFC (1996) Introduction to quantitative genetics (4 ${ }^{\text {th }}$ ed.). Longman Limited, Harlow

Franklin DR, Smith Jr LL (1963) Early life history of the northern pike, Esox lucius L, with special reference to the factors influencing the numerical strength of year classes. Trans Am Fish Soc 92:91-110

Grey DR (1993) Evolutionarily stable optimal harvest strategies. In Stokes TK, McGlade JM, Law R (eds) The exploitation of evolving resources. Springer-Verlag, Berlin. pp176186

Haugen TO, Winfield IJ, Vøllestad LA, Fletcher JM, James JB, Stenseth NC (2007) Density dependence and density independence in the demography and dispersal of pike over four decades. Ecol Monogr 77:483-502

Heino M (1998) Management of evolving fish stocks. Can J Fish Aquat Sci 55:1971-1982

Heino M, Dieckmann U (2008) Detecting fisheries-induced life-history evolution: an overview of the reaction norm approach. Bull Mar Sci 83:69-93

Heino M, Godø OR (2002) Fisheries-induced selection pressures in the context of sustainable fisheries. Bull Mar Sci 70:639-656 
1 Hereford J, Hansen TF, Houle D (2004) Comparing strengths of directional selection: how strong is strong? Evolution 58:2133-2143

Hilborn R, Minte-Vera CV (2008) Fisheries-induced changes in growth rates in marine fisheries: are they significant? Bull Mar Sci 83:95-105

Hutchings JA, Fraser DJ (2007) The nature of fisheries- and farming-induced evolution. Mol Ecol 17:295-313

Jørgensen C, Enberg K, Dunlop ES, Arlinghaus R, Boukal DS, Brander K, Ernande B, Gårdmark A, Johnston F, Matsumura S, Pardoe H, Raab K, Silva A, Vainikka A, Dieckmann U, Heino M, Rijnsdorp AD (2007) Managing evolving fish stocks. Science 318:12471248

Jørgensen C, Ernande B, Fiksen $\varnothing$ (2009) Size-selective fishing gear and life history evolution in the Northeast Arctic cod. Evol Appl 2:356-370

Kinnison MT, Palkovacs EP, Darimont CT, Carlson SM, Paquet PC, Wilmers CC (2009) Some cautionary notes on fisheries evolutionary impact assessments. Proc Nat Acad Sci USA 106:E115

Kipling C (1983a) Changes in the growth of pike (Esox lucius) in Windermere. J Anim Ecol $52: 647-657$

Kipling C (1983b) Changes in the population of pike (Esox lucius) in Windermere from 1944 to 1981. J Anim Ecol 52:989-999

Kipling C, Frost, WE (1970) A study of the mortality, population numbers, year class strength, production and food consumption of pike, Esox lucius L., in Windermere from 1944 to 1962. J Anim Ecol 39:115-157

Kuparinen A, Merilä J (2007) Detecting and managing fisheries-induced evolution. Trends Ecol Evol 22:652-659 
1 Law R (2007) Fisheries-induced evolution: present status and future directions. Mar Ecol Prog Ser 335:271-277

3 Law R, Grey DR (1989) Evolution of yields from populations with age-specific cropping. Evol Ecol 3:343-359

Lester NP, Shuter BJ, Abrams PA (2004) Interpreting the von Bertalanffy model of somatic growth in fishes: the cost of reproduction. Proc R Soc Lond B 271:1625-1631

Lewin W-C, Arlinghaus R, Mehner T (2006) Documented and potential biological impacts of recreational fishing: insights for management and conservation. Rev Fish Sci 14:305367

Lorenzen K, Enberg K (2002) Density-dependent growth as a key mechanism in the regulation of fish populations: evidence from among-population comparisons. Proc R Soc

Mace PM (1994) Relationships between common biological reference points used as thresholds and targets of fisheries management strategies. Can J Fish Aquat Sci 51:110-122

Minns CK, Randall RG, Moore JE, Cairns VW (1996) A model simulating the impact of habitat supply limits on northern pike, Esox lucius, in Hamilton Harbour, Lake Ontario.

Munoeke MI, Childress WM (1994) Hooking mortality: a review for recreational fisheries. Rev Fish Sci 2:123-156

Nusslé S, Bornand CN, Wedekind C (2008) Fishery-induced selection on an Alpine whitefish: quantifying genetic and environmental effects on individual growth rate. Evol Appl 1:1- 
1 Okamoto KW, Whitlock R, Magnan P, Dieckmann U (2009) Mitigating fisheries-induced evolution in lacustrine brook charr (Salvelinus fontinalis) in southern Quebec, Canada. Evol Appl 2:415-437

Paukert CP, Klammer JA, Pierce RB, Simonson TD (2001) An overview of northern pike regulations in North America. Fisheries 26:6-13

Philipp DP,Cooke SJ, Claussen JE, Koppelman JB, Suski CD, Burkett DP (2009) Selection for vulnerability to angling in largemouth bass. Trans Am Fish Soc 138:189-199

Phillips PC, Arnold SJ (1989) Visualizing multivariate selection. Evolution 43:1209-1222

Pierce RB, Tomcko CM, Schupp DH (1995) Exploitation of northern pike in seven small North-Central Minnesota lakes. N Am J Fish Manage 15:601-609

Post JR, Mushens C, Paul A, Sullivan M (2003) Assessment of alternative harvest regulations for sustaining recreational fisheries: model development and application to bull trout. $\mathrm{N}$ Am J Fish Manage 23:22-34

Quince C, Abrams PA, Shuter BJ, Lester NP (2008) Biphasic growth in fish I: theoretical foundations. J Theor Biol 254:197-206

Raat AJP (1988) Synopsis of biological data on the northern pike Esox lucius Linnaeus, 1758. FAO Fish. Synop. 30, Rev. 2. FAO, Rome, Italy

Redpath TD, Cooke SJ, Arlinghaus R, Wahl DH, Philipp DP (2009) Life-history traits and energetic status in relation to vulnerability to angling in an experimentally selected teleost fish. Evol Appl 2:312-323

Ricker WE (1981) Changes in the Average Size and Average Age of Pacific Salmon. Can J Fish Aquat Sci 38:1636-1656 
1 Saura M, Morán P, Brotherstone S, Caballero A, Álvarez J, Villanueva B (2010) Predictions of response to selection caused by angling in a wild population of Atlantic salmon (Salmo salar). Freshwat Biol 55: 923-930

Sharpe DMT, Hendry AP (2009) Life history change in commercially exploited fish stocks: an analysis of trends across studies. Evol Appl 2:260-275

Stamps JA (2007) Growth-mortality tradeoffs and 'personality traits' in animals. Ecol Lett $10: 355-363$

Swain DP, Sinclair AF, Hanson MF (2007) Evolutionary response to size-selective mortality in an exploited fish population. Proc R Soc B 274:1015-1022

Thériault V, Dunlop ES, Dieckmann U, Bernatchez L, Dodson JJ (2008) The impact of fishing-induced mortality on the evolution of alternative life-history tactics in brook charr. Evol Appl 1:409-423

Thygesen UH, Farnsworth KD, Andersen KH, Beyer JE (2005) How optimal life history changes with the community size-spectrum. Proc R Soc B 272:1323-1331

Uusi-Heikkilä S, Wolter C, Klefoth T, Arlinghaus R (2008) A behavioral perspective of fishing-induced evolution. Trends Ecol Evol 23:419-421

Walters CJ, Martell SJD (2004) Fisheries ecology and management. Princeton University Press, New Jersey

Williams EH, Shertzer KW (2005) Effects of fishing on growth traits: a simulation analysis. Fish Bull 103:392-403

Willis DW (1989) Proposed standard length-weight equation for northern pike. N Am J Fish Manage 9:203-208 


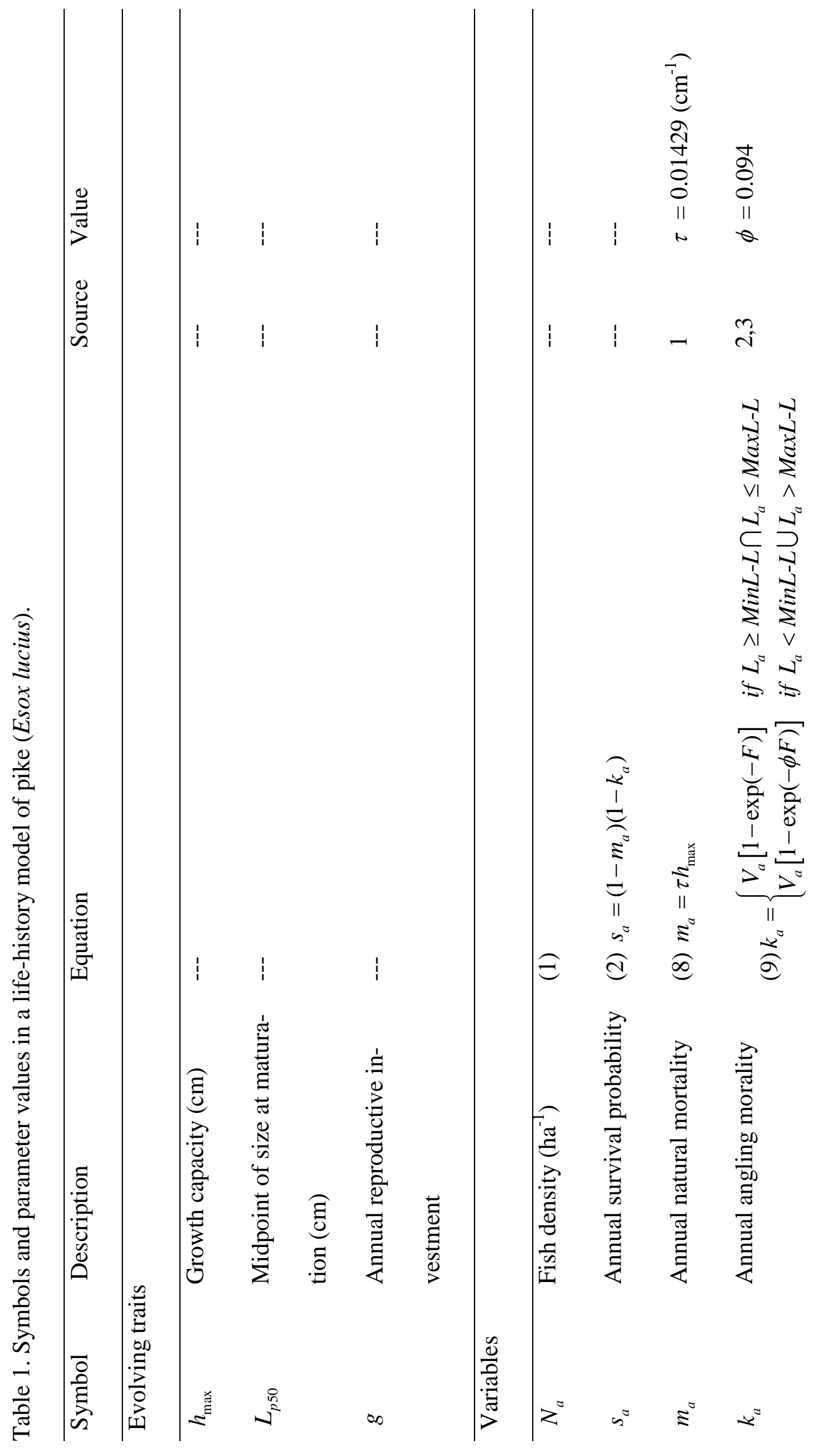



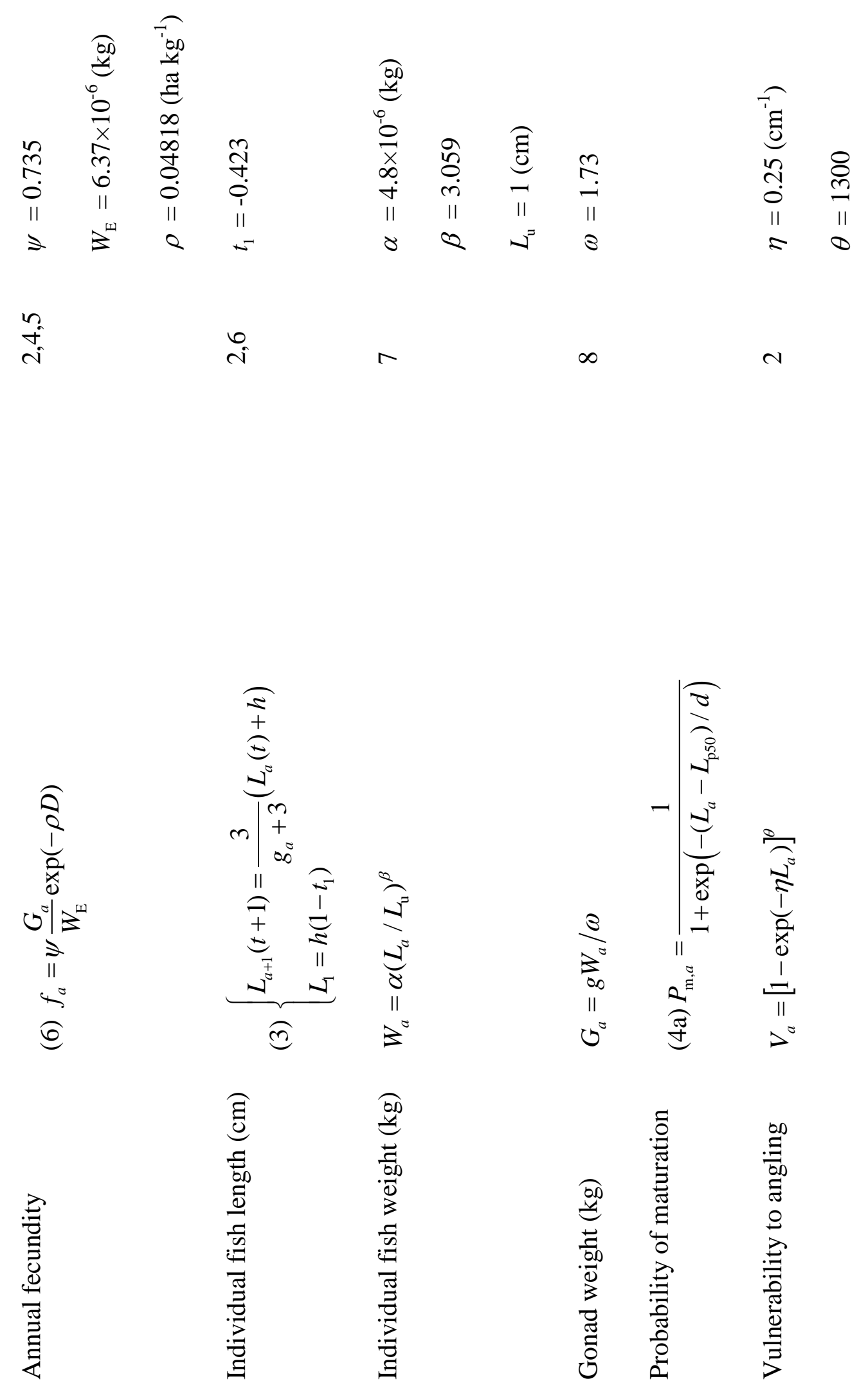

$4^{\circ} \quad \nabla^{\circ} \quad 0^{\circ} e^{\circ} \lambda^{\circ}$ 


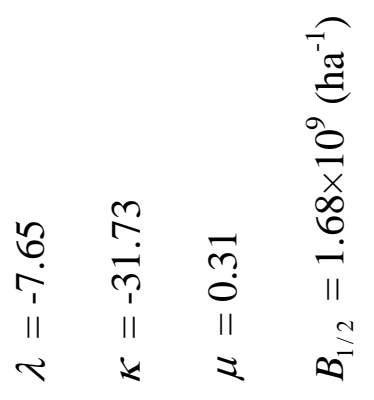

$$
\begin{aligned}
& a
\end{aligned}
$$

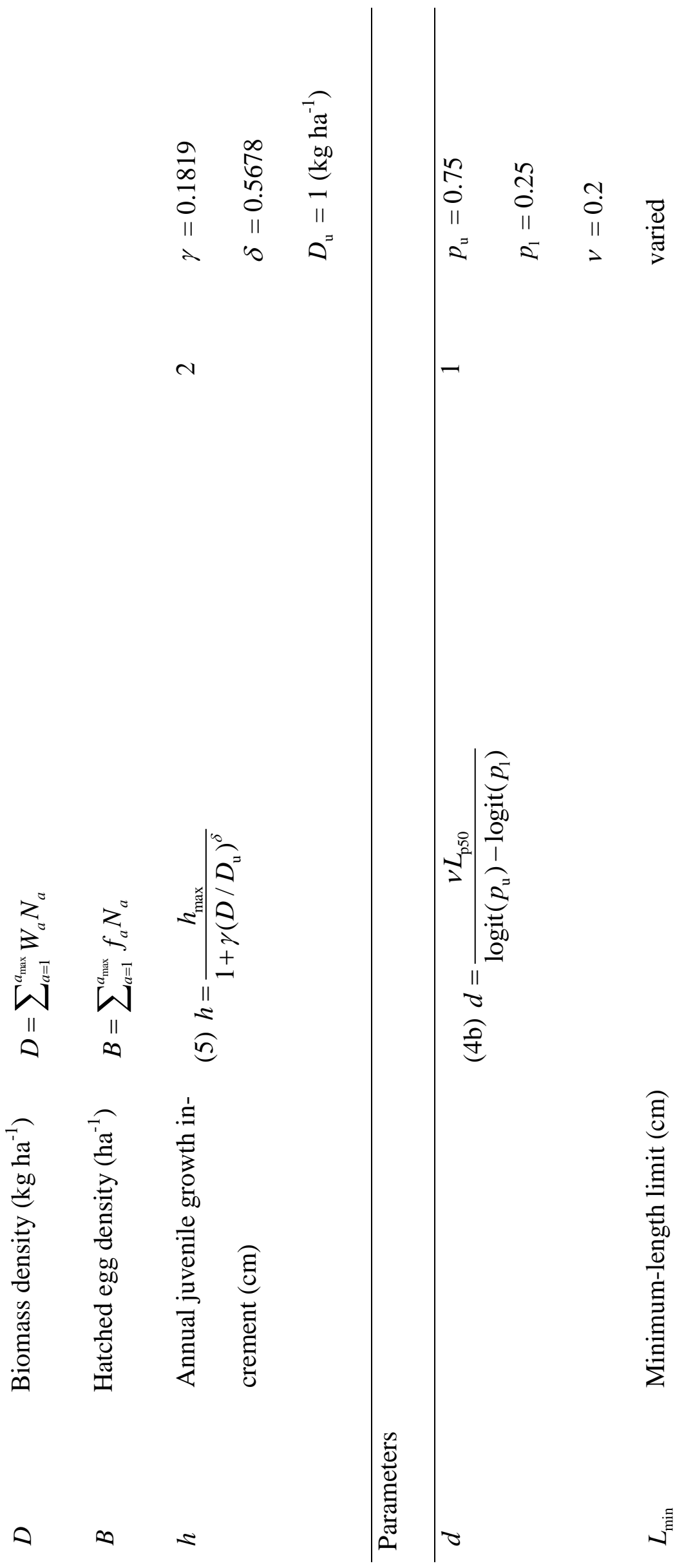

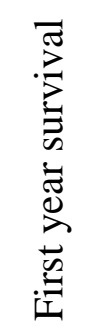

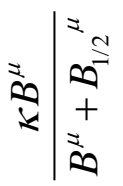

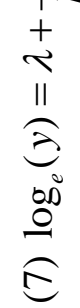

$\lambda$

$0 \quad 0=$

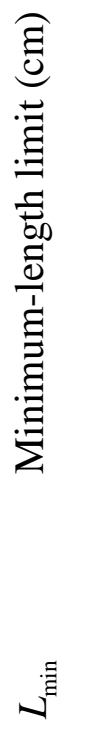




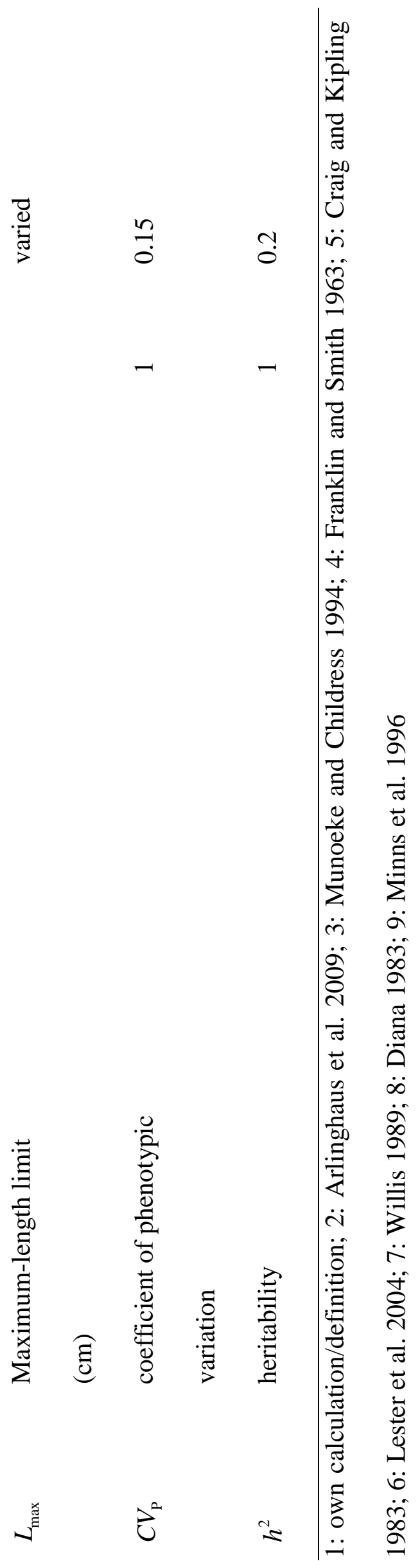


Table 2. Population means of the three life-history traits (reproductive investment, growth capacity, and size at maturation) at evolutionary equilibrium in the absence of angling pressures in pike (Esox lucius). The default parameter values (Table 1) are used. The densities and age at first spawning are also shown.

\begin{tabular}{|c|c|c|c|c|c|c|}
\hline & \multirow[b]{2}{*}{$g$} & \multirow[b]{2}{*}{$h_{\max }(\mathrm{cm})$} & \multirow[b]{2}{*}{$L_{\mathrm{p} 50}(\mathrm{~cm})$} & \multicolumn{3}{|c|}{ At equilibrium } \\
\hline & & & & $\begin{array}{l}\text { fish density } \\
\qquad\left(\mathrm{ha}^{-1}\right)\end{array}$ & $\begin{array}{c}\text { biomass density } \\
\left(\mathrm{kg} \mathrm{ha}^{-1}\right)\end{array}$ & $\begin{array}{c}\text { age at first } \\
\text { spawning (yr) }\end{array}$ \\
\hline EP-1 & 0.433 & 30.0 & $<12 *$ & 12.0 & 7.8 & $2(100 \%)$ \\
\hline EP-2 & 0.471 & 27.1 & 39.4 & 13.4 & 9.0 & $\begin{array}{l}3(42 \%), \\
4(57 \%)\end{array}$ \\
\hline
\end{tabular}

* Individuals with $L_{\mathrm{p} 50}$ of less than $12 \mathrm{~cm}$ are phenotypically equivalent because they mature (i.e., start investing to reproduction) at the age of 1 year with a probability of $100 \%$. 
Table 3. Sensitivity analysis in terms of percent changes in selection differentials on the three life-history traits when the default value of each parameter is altered by $\pm 10 \%$. Changes in response variables $\geq|10 \%|$ (i.e., sensitive or elastic changes) are highlighted in bold. We chose an intermediate angling intensity ( $F=0.67)$ with no harvest regulation.

\begin{tabular}{lrrrrrr}
\hline \multirow{2}{*}{ Parameters } & \multicolumn{2}{c}{$\begin{array}{c}\text { Reproductive } \\
\text { investment } g\end{array}$} & \multicolumn{2}{c}{$\begin{array}{c}\text { Growth capacity } \\
\text { max }\end{array}$} & \multicolumn{3}{c}{ Size at maturation } \\
& $+10 \%$ & $-10 \%$ & $+10 \%$ & $-10 \%$ & $+10 \%$ & $-10 \%$ \\
\hline$\alpha$ & 0.2 & -0.3 & -4.7 & 8.4 & 1.1 & -0.3 \\
$\beta$ & $\mathbf{- 1 7 . 5}$ & 10.2 & $\mathbf{9 9 . 1}$ & $\mathbf{5 2 . 3}$ & $\mathbf{3 9 . 7}$ & $\mathbf{1 3 . 4}$ \\
$\gamma$ & 0.1 & -0.1 & -2.6 & 3.5 & 0.4 & -0.2 \\
$\delta$ & 0.0 & 0.0 & 0.2 & -0.2 & 0.0 & 0.0 \\
$t_{1}$ & 0.0 & -0.1 & $\mathbf{1 3 . 3}$ & -8.7 & 4.4 & -3.8 \\
$\omega$ & -0.2 & 0.2 & 5.6 & -4.1 & -0.3 & 0.8 \\
$w_{\mathrm{E}}$ & -0.2 & 0.2 & 5.6 & -4.1 & -0.3 & 0.8 \\
$\psi$ & 0.2 & -0.2 & -3.8 & 6.3 & 0.7 & -0.3 \\
$\rho$ & 0.0 & 0.0 & 0.2 & -0.2 & 0.0 & 0.0 \\
$\lambda$ & -2.4 & 1.7 & $\mathbf{9 0 . 2}$ & $\mathbf{2 8 . 1}$ & 5.5 & $\mathbf{3 0 . 5}$ \\
$\kappa$ & -0.2 & 0.2 & 5.6 & -4.2 & -0.3 & 0.9 \\
$\mu$ & 0.6 & -0.7 & -5.9 & $\mathbf{2 9 . 1}$ & 5.2 & 0.9 \\
$B_{1 / 2}$ & 0.1 & -0.1 & -1.4 & 1.7 & 0.2 & -0.1 \\
$\nu$ & -0.2 & 0.2 & 2.4 & -3.0 & 1.4 & -2.0 \\
$\tau$ & -5.0 & 4.8 & $\mathbf{2 2 . 5}$ & -8.1 & -9.6 & $\mathbf{1 6 . 9}$ \\
$\eta$ & -0.5 & 0.9 & $\mathbf{5 4 . 1}$ & $\mathbf{1 2 . 6}$ & -0.8 & 4.6 \\
$\theta$ & 0.1 & -0.1 & -3.3 & 5.2 & 0.3 & -0.3 \\
$\phi$ & 0.0 & 0.0 & 0.0 & 0.0 & 0.0 & 0.0 \\
\hline
\end{tabular}




\section{Figure captions}

Fig. 1. a) Probability of maturation in relation to size $\left(L_{\mathrm{p} 50}=41.52, p_{\mathrm{u}}=0.75, p_{1}=0.25\right.$, and $v=0.2$ ). b) Examples of fish growth trajectories when annual reproductive investment $g=0.4709$ (the default value, filled circles) and $g=0.6$ (open circles) in unexploited (continuous lines) and exploited populations (dotted lines). c) Default trade-off relationship between growth capacity $\left(h_{\max }\right)$ and annual survival probability $\left(1-\tau h_{\max }\right)$. d) Vulnerability to angling in relation to fish size. In addition to the default vulnerability curve (continuous line), an alternative trophy vulnerability curve used in robustness analysis is shown (dashed line).

Fig. 2. a) Standardized selection differentials $\left(S_{\text {std }}\right)$ on annual reproductive investment ( $g$ ), growth capacity $\left(h_{\max }\right)$, and size at maturation $\left(L_{\mathrm{p} 50}\right)$ in relation to the instantaneous fishing mortality $(F)$. b) Yield and exploitation rate (among fish of age 1 year or older) in relation to the instantaneous fishing mortality $(F)$.

Fig. 3. Influence of different harvest regulation on standardized selection differentials $\left(S_{\text {std }}\right)$ on annual reproductive investment ( $g$, top), growth capacity ( $h_{\max }$, middle), and size at maturation ( $L_{\mathrm{p} 50}$, bottom). In the right, small plots show the baseline case with no harvest regulation. In the left three plots (a-c), minimum-length limits are changed between 45 and $100 \mathrm{~cm}$. In the central three plots (d-f), maximum-length limits are changed between 100 and $50 \mathrm{~cm}$ in combination with a minimum-length limit of $45 \mathrm{~cm}$ (i.e., harvestable-slot length limits). In the right three plots (g-i), maximum-length limits are changed between 100 and $50 \mathrm{~cm}$. In every plot, regulations are getting tighter from left to right. Three different degrees of instantaneous fishing 
morality ( $F$ ) are used: 0.33 (dotted lines), 0.67 (dashed lines) and 1.0 (continuous lines).

Fig. 4. Influence of different harvest regulation on standardized selection differentials $\left(S_{\text {std }}\right)$ on annual reproductive investment ( $g$, top), growth capacity ( $h_{\max }$, middle), and size at maturation ( $L_{\mathrm{p} 50}$, bottom). Selection differentials are shown when the population is exploited towards different levels of SPR (spawning potential ratio), 0.50 (dotted lines), 0.35 (dashed lines), or 0.2 (continuous lines). The SPR index indicates the degree of reduction of the exploited spawner biomass relative to the unexploited case, and a value $\leq 0.35$ is supposed to indicate recruitment overfishing (Mace 1994). In the right small plots show the baseline case with no harvest regulation. In the left three plots (a-c), minimum-length limits are changed between 45 and $100 \mathrm{~cm}$. In the central three plots (d-f), maximum-length limits are changed between 100 and $50 \mathrm{~cm}$ in combination with a minimum-length limit of $45 \mathrm{~cm}$ (i.e., harvestable-slot length limits). In the right three plots (g-i), maximum-length limits are changed between 100 and $50 \mathrm{~cm}$. In every plot, regulations are getting tighter from left to right.

Fig. 5. Changes of the population means of the life-history traits (top), fish length at the age of 4 years (middle), and yield (harvest biomass) (bottom) during 100 years of consistent exploitation with particular harvest regulations. Instantaneous mortality is fixed to $F=0.67$. In (a), the default selectivity is assumed. In (b), "trophy" or large-size targeting selectivity is assumed (see Fig. 1d).

Fig. 6. Influence of different harvest regulation on fish length at the age of 4 years (top), yield (upper middle), population biomass (lower middle), and population pristine biomass (bottom). The values after 100 years of the evolution (continuous line) and 
at the evolutionary endpoints (dashed line) are shown. In the right, small plots show the baseline case with no harvest regulation. In the left four plots (a-d), minimumlength limits are changed between 45 and $100 \mathrm{~cm}$. In the central four plots (e-h), maximum-length limits are changed between 100 and $50 \mathrm{~cm}$ in combination with a minimum-length limit of $45 \mathrm{~cm}$ (i.e., harvestable-slot length limits). In the right four plots (i-1), maximum-length limits are changed between 100 and $50 \mathrm{~cm}$. Instantaneous morality is fixed to $F=0.67$.

Fig. 7. Long-term changes of the population means of the life-history traits (top) and fish length at the age of 4 years (bottom) during 1500 years of consistent exploitation. A minimum-length limit of $45 \mathrm{~cm}$ is applied, and instantaneous morality is fixed to $F$ $=0.67$.

Fig. 8. Changes of the population means of the life-history traits after 100 years of consistent exploitation with no harvest regulation. Heritability and phenotypic variability are systematically varied. Instantaneous morality is fixed to $F=0.67$. 

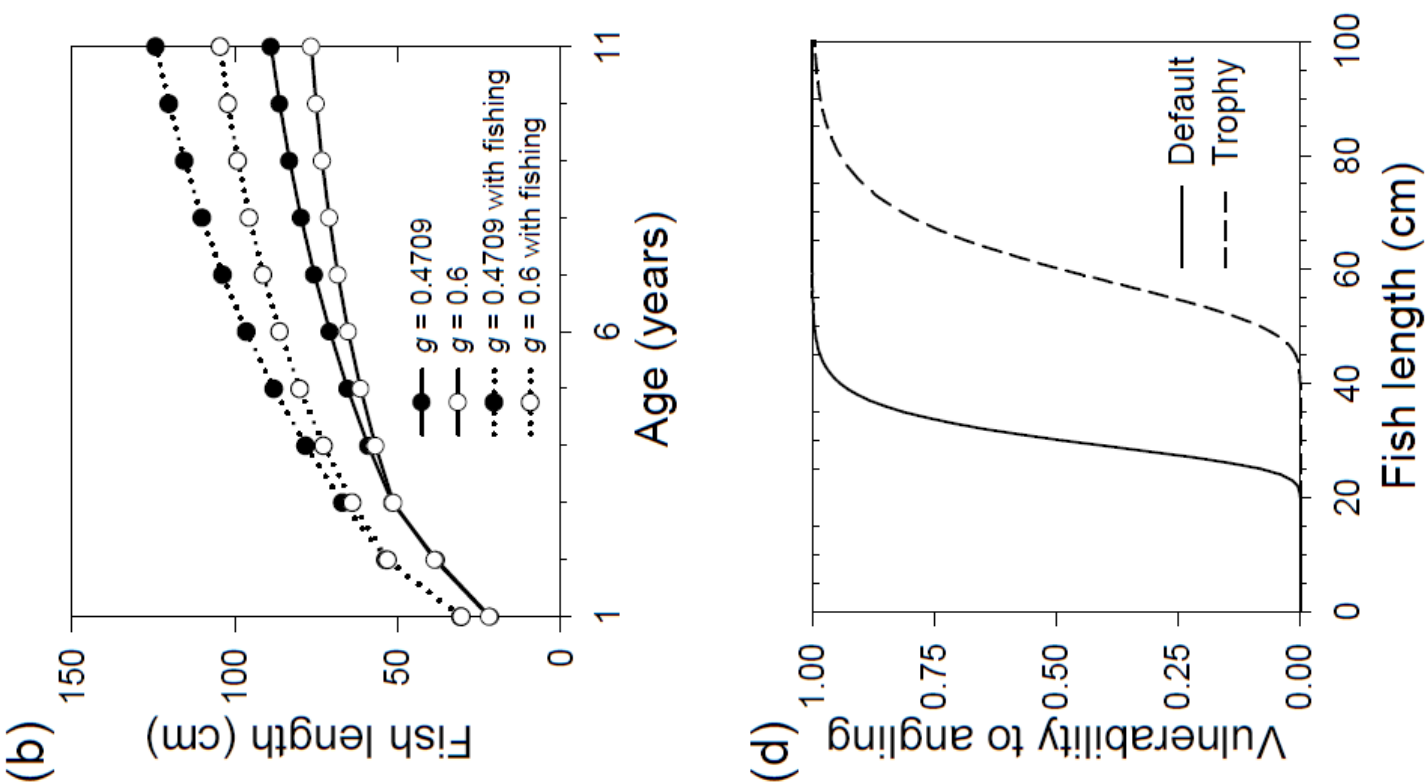

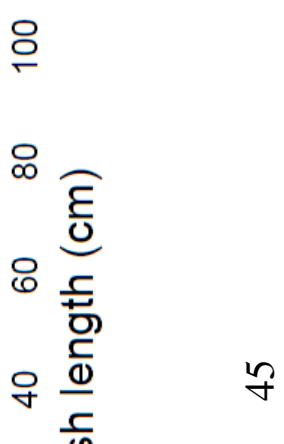

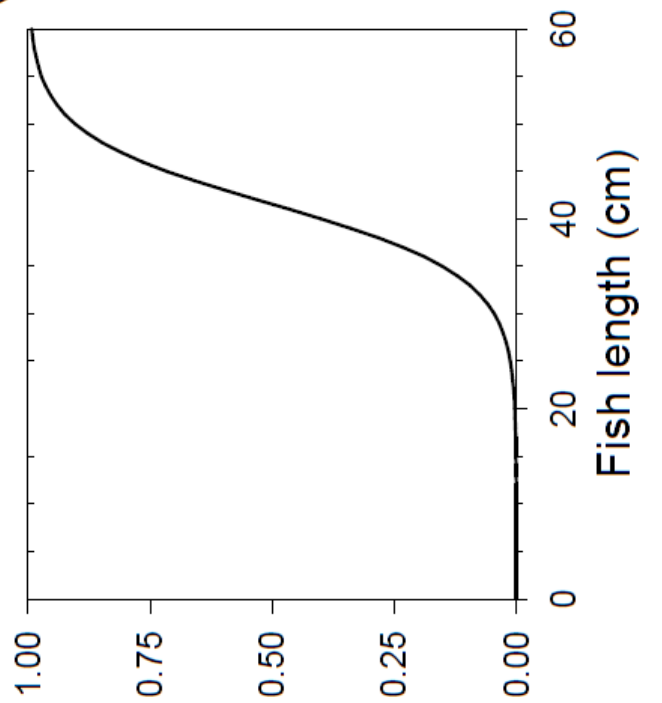

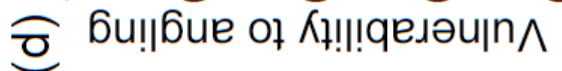

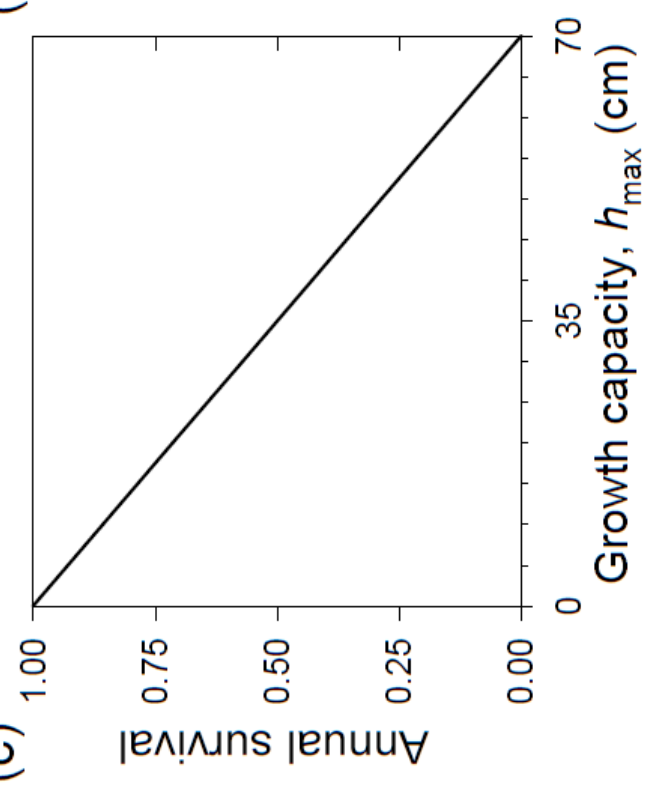

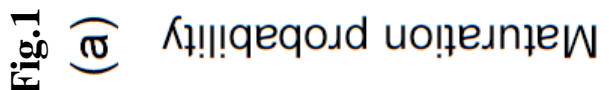




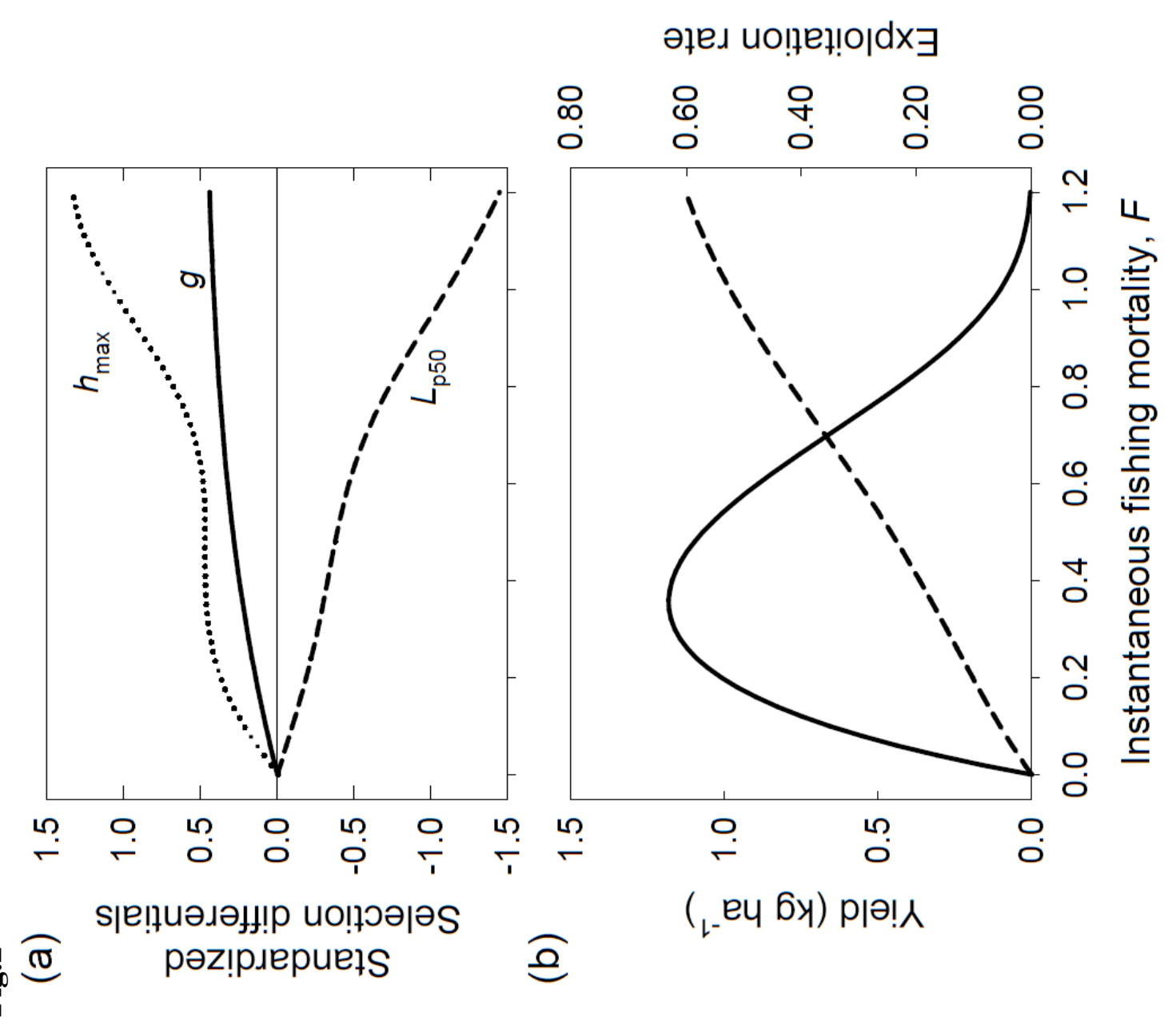




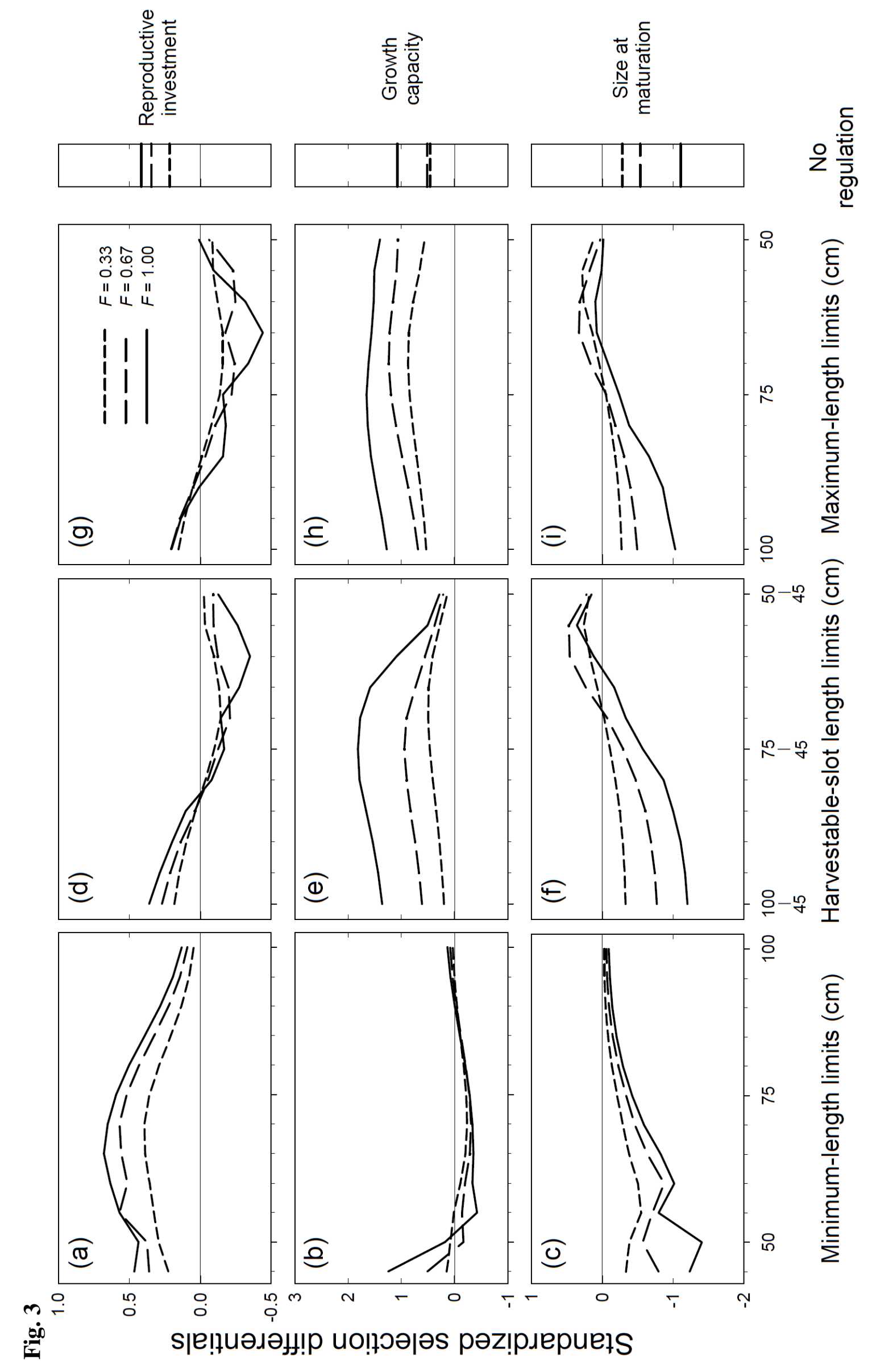




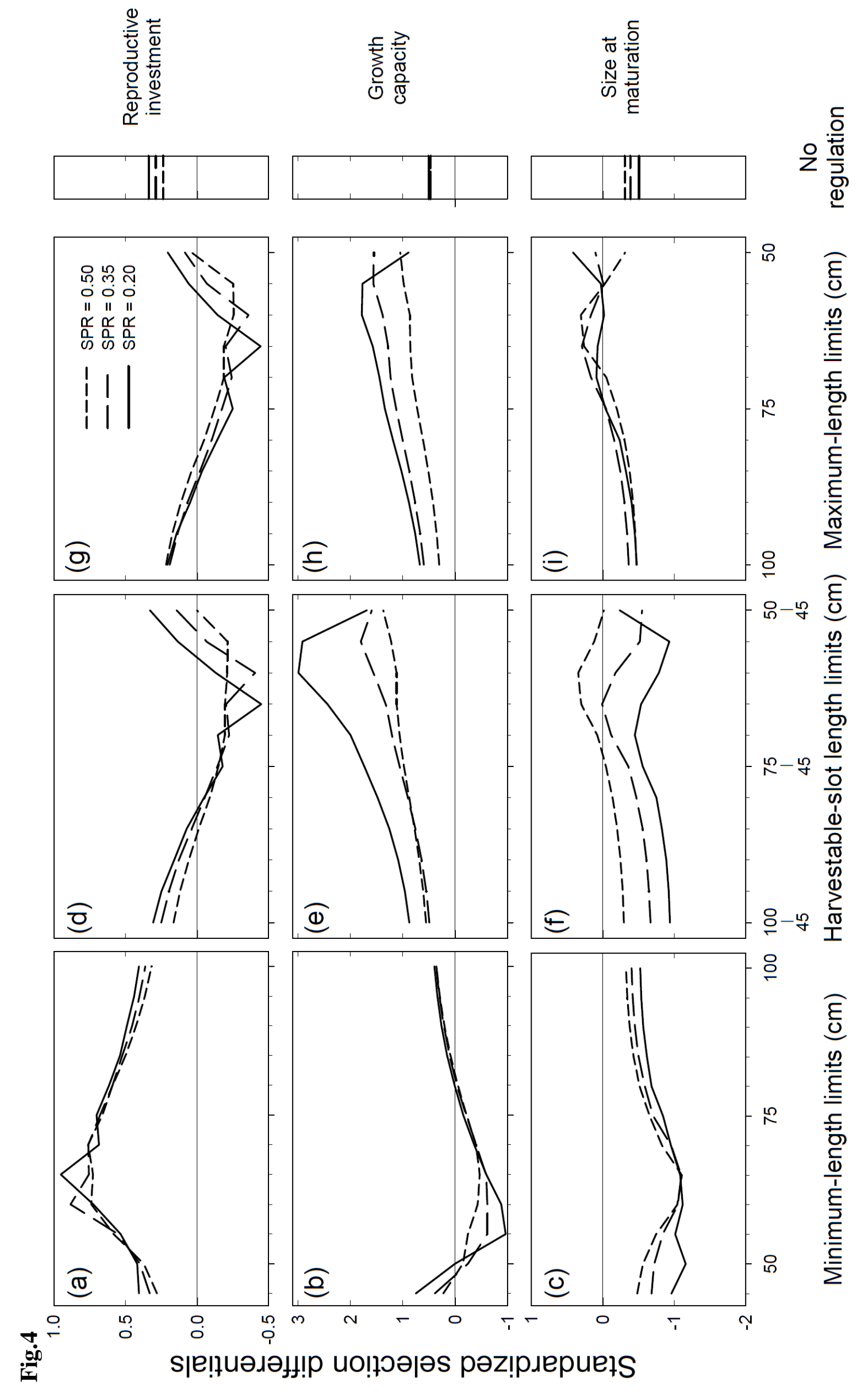



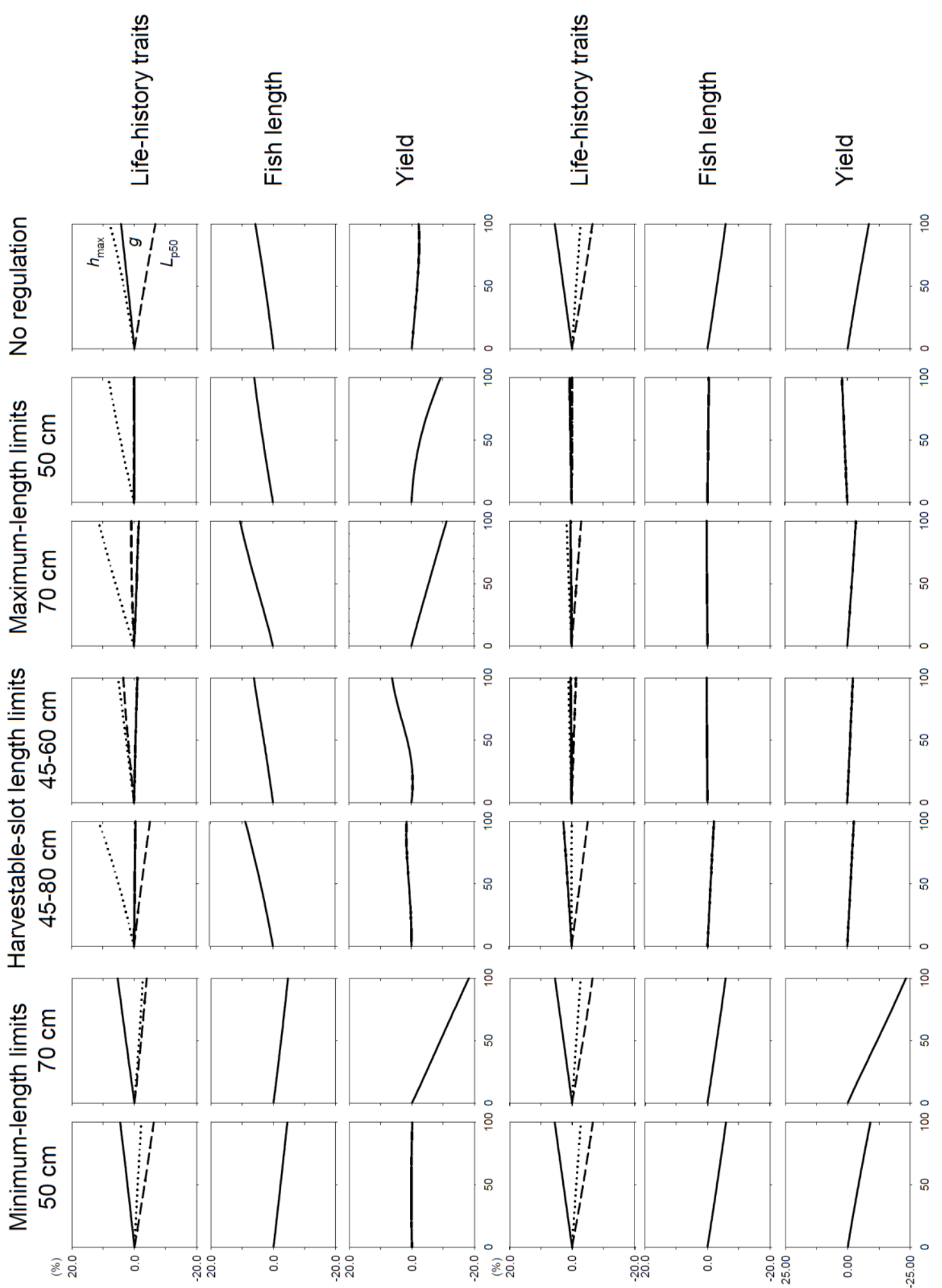

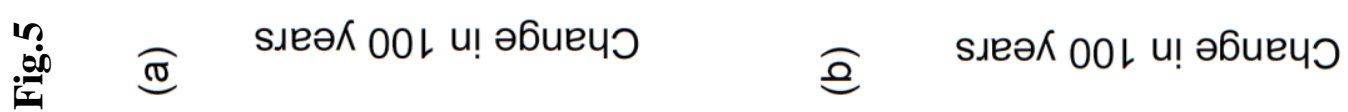



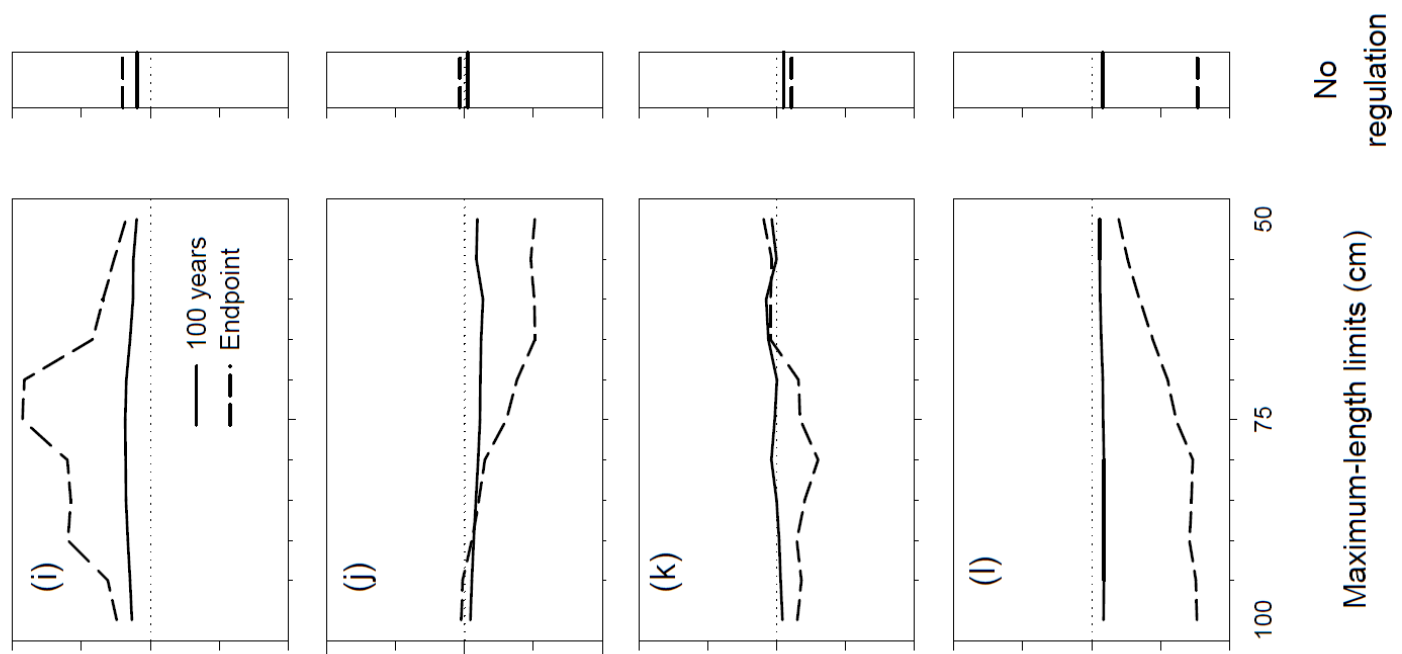

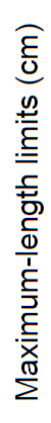
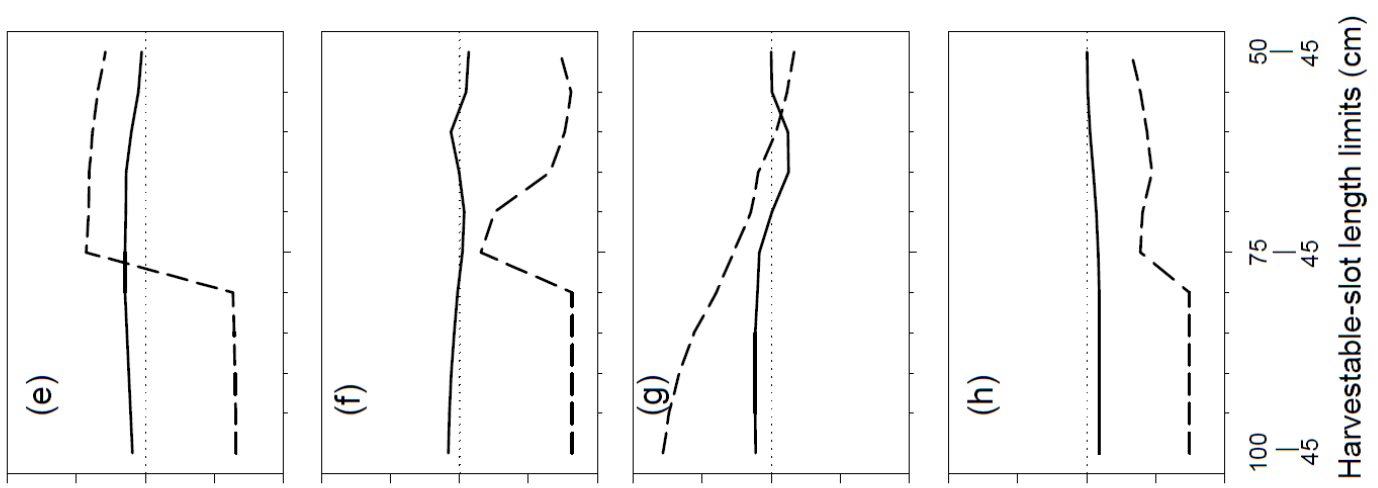

오
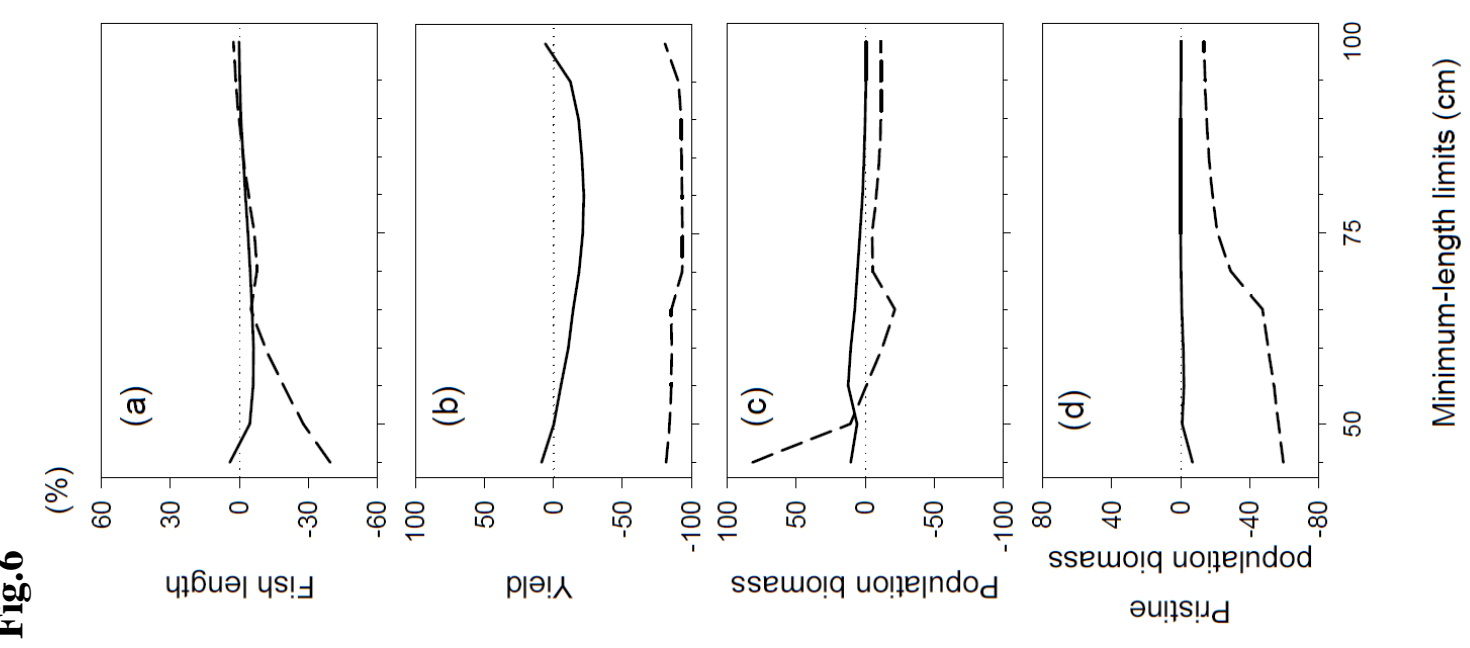
$\bar{n}$

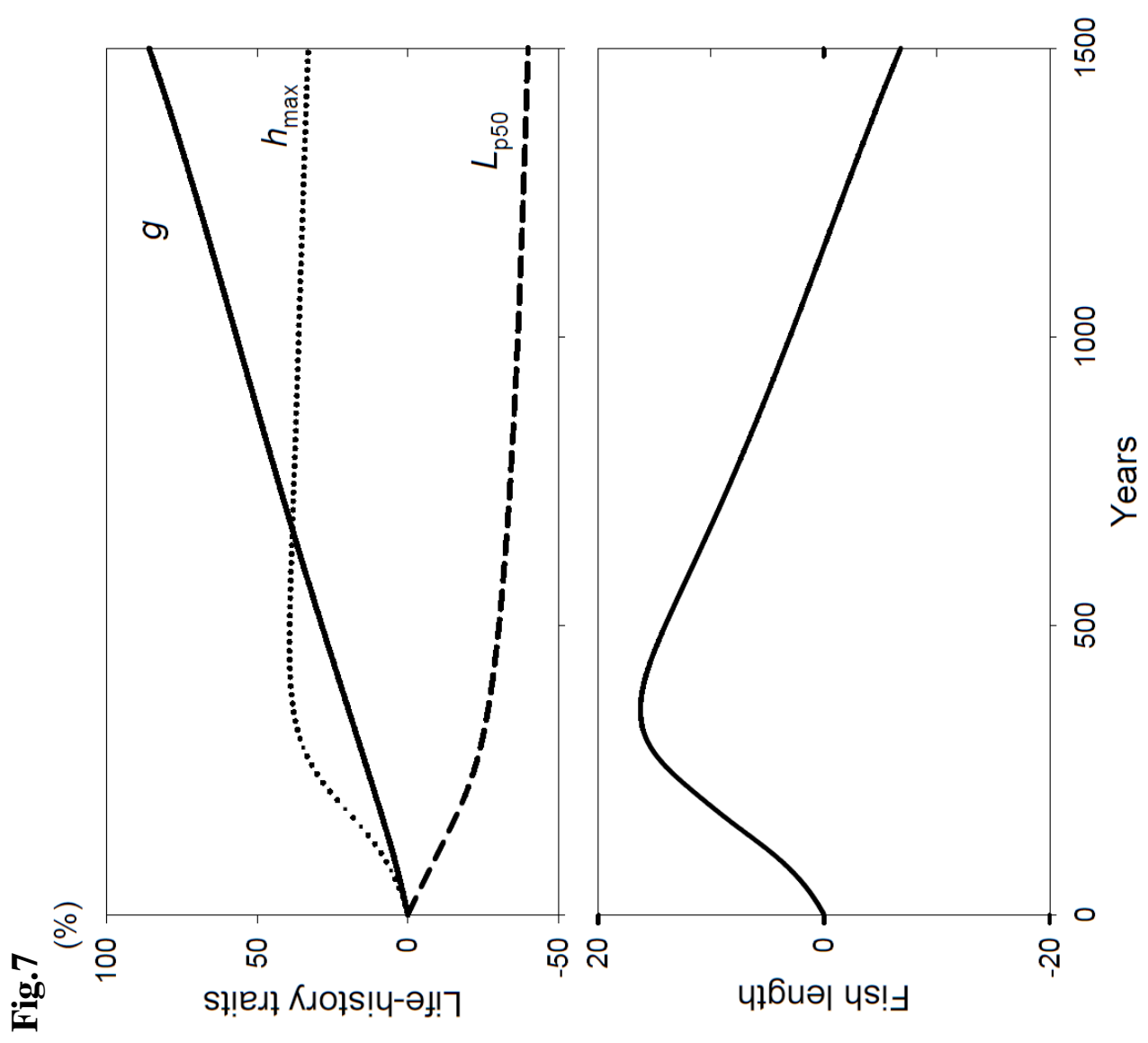




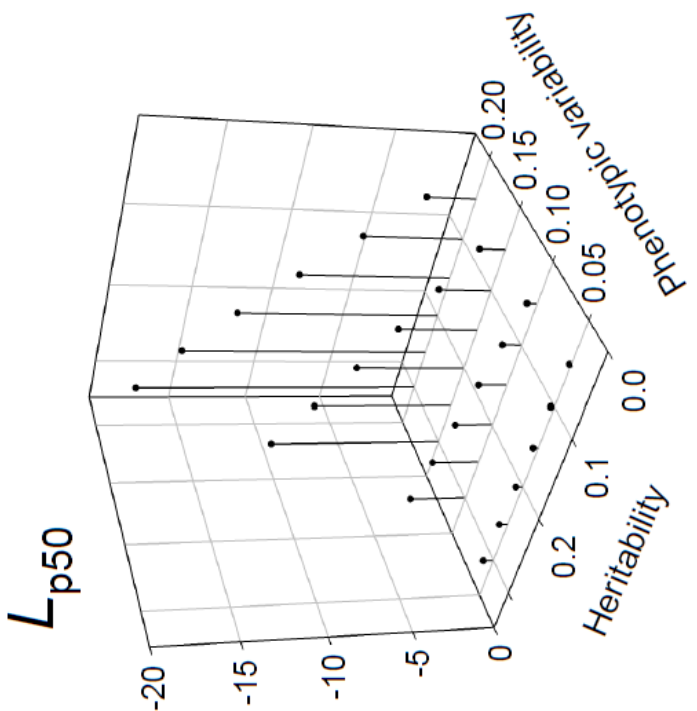

(\%) sıеәК 00L u! әбиечว

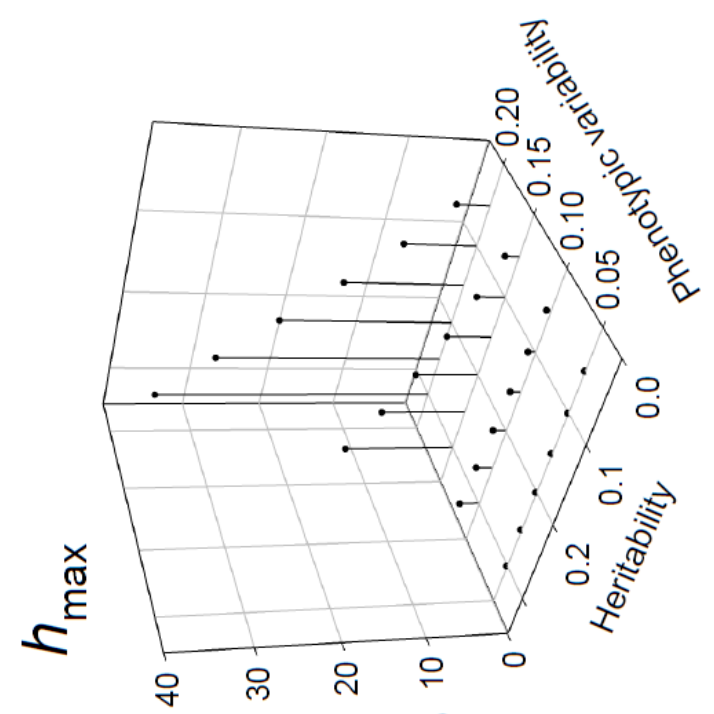

(\%) sıeəК 00L u! әБиечว

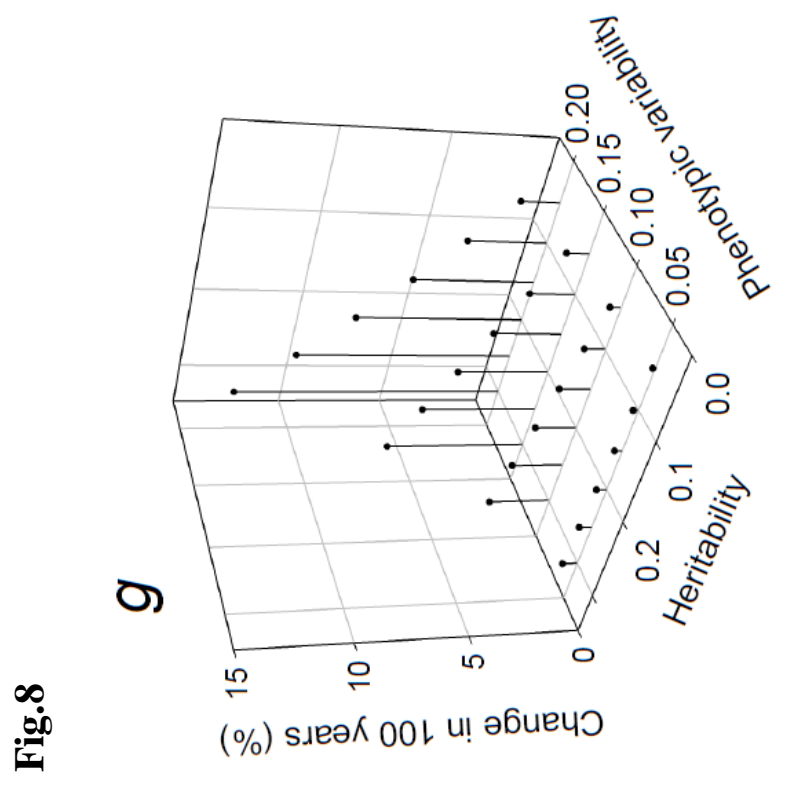

